\title{
Model development of dust emission and heterogeneous chemistry within the Community Multiscale Air Quality modeling system and its application over East Asia
}

\author{
Xinyi Dong ${ }^{1}$, Joshua S. Fu ${ }^{1,2}$, Kan Huang ${ }^{1}$, Daniel Tong ${ }^{3,4,5}$, and Guoshun Zhuang ${ }^{6}$ \\ ${ }^{1}$ Department of Civil and Environmental Engineering, the University of Tennessee, Knoxville, TN 37996, USA \\ ${ }^{2}$ Climate Change Science Institute, Oak Ridge National Laboratory, Oak Ridge, TN 37831, USA \\ ${ }^{3}$ NOAA/OAR/ARL, NOAA Center for Weather and Climate Prediction, College Park, MD 20740, USA \\ ${ }^{4}$ Center for Spatial Information Science and Systems, George Mason University, Fairfax, VA 22030, USA \\ ${ }^{5}$ Cooperative Institute for Climate and Satellites, University of Maryland, College Park, MD 20740, USA \\ ${ }^{6}$ Center for Atmospheric Chemistry Study, Department of Environmental Science and Engineering, Fudan University, \\ Shanghai 200433, China
}

Correspondence to: Joshua S. Fu (jsfu@utk.edu)

Received: 22 September 2015 - Published in Atmos. Chem. Phys. Discuss.: 17 December 2015

Revised: 13 May 2016 - Accepted: 30 May 2016 - Published: 6 July 2016

\begin{abstract}
The Community Multiscale Air Quality (CMAQ) model has been further developed in terms of simulating natural wind-blown dust in this study, with a series of modifications aimed at improving the model's capability to predict the emission, transport, and chemical reactions of dust. The default parameterization of initial threshold friction velocity constants are revised to correct the double counting of the impact of soil moisture in CMAQ by the reanalysis of field experiment data; source-dependent speciation profiles for dust emission are derived based on local measurements for the Gobi and Taklamakan deserts in East Asia; and dust heterogeneous chemistry is also implemented. The improved dust module in the CMAQ is applied over East Asia for March and April from 2006 to 2010. The model evaluation result shows that the simulation bias of $\mathrm{PM}_{10}$ and aerosol optical depth (AOD) is reduced, respectively, from -55.42 and $-31.97 \%$ by the original CMAQ to -16.05 and $-22.1 \%$ by the revised CMAQ. Comparison with observations at the nearby Gobi stations of Duolun and Yulin indicates that applying a source-dependent profile helps reduce simulation bias for trace metals. Implementing heterogeneous chemistry also results in better agreement with observations for sulfur dioxide $\left(\mathrm{SO}_{2}\right)$, sulfate $\left(\mathrm{SO}_{4}^{2-}\right)$, nitric acid $\left(\mathrm{HNO}_{3}\right)$, nitrous oxides $\left(\mathrm{NO}_{x}\right)$, and nitrate $\left(\mathrm{NO}_{3}^{-}\right)$. The investigation of a severe dust storm episode from 19 to 21 March 2010 suggests that the
\end{abstract}

revised CMAQ is capable of capturing the spatial distribution and temporal variation of dust. The model evaluation also indicates potential uncertainty within the excessive soil moisture used by meteorological simulation. The mass contribution of fine-mode particles in dust emission may be underestimated by $50 \%$. The revised CMAQ model provides a useful tool for future studies to investigate the emission, transport, and impact of wind-blown dust over East Asia and elsewhere.

\section{Introduction}

Natural dust has a wide impact on many different aspects of the Earth's system. It reduces atmospheric visibility (Engelstaedter et al., 2003; Kurosaki and Mikami, 2005; Washington et al., 2003), deteriorates air quality (De Longueville et al., 2010; Prospero, 1999), alters the radiative forcing budget (Liao et al., 2004; Miller et al., 2006; Reddy et al., 2005), and also affects the cloud properties and precipitation (Rosenfeld et al., 2001; Forster et al., 2007). Over East Asia, spring time dust storms often lead to severe air pollution since the intensively elevated aerosol loadings are dumped over the most populated areas. The estimated global source of mineral dust with diameters below $10 \mu \mathrm{m}$ is between 1000 and 
$4000 \mathrm{Tg}$ year $^{-1}$ on a global scale as reported by Intergovernmental Panel on Climate Change (IPCC), and Zhang et al. (2003) reported annual Asian dust emission as $800 \mathrm{Tg}$. East Asian dust mainly originates from two dominant source regions and their surrounding areas, including the Taklamakan Desert in northwest China and the Gobi Desert in Mongolia and northern China (Huang et al., 2010). In spring, the Mongolian cyclone associated with the East Asian trough often leads to strong northwesterly near-surface winds (Shao and Dong, 2006) that lift and transport the eolian dust particles. East Asian dust can be transported to densely populated areas over China (Qian et al., 2002), South Korea (Chun et al., 2001; Park and In, 2003), and Japan (Ma et al., 2001; Uno et al., 2001) and at times can even be transported across the Pacific Ocean, reaching as far as the west coast of North America (Fairlie et al., 2010; Wang et al., 2012; Zhao et al., 2010). Along the transport pathway, mineral dust particles also serve as carriers and reaction platforms by taking up reactive gases such as ozone $\left(\mathrm{O}_{3}\right)$, nitrogen oxides $\left(\mathrm{NO}_{x}\right)$, sulfur dioxide $\left(\mathrm{SO}_{2}\right)$, nitric acid $\left(\mathrm{HNO}_{3}\right)$, hydroxyl radicals $(\mathrm{OH})$, and volatile organic compounds (VOCs). The heterogeneous dust chemistry may change the photochemistry, acid deposition, and production of secondary aerosols in the atmosphere. Moreover, East Asian dust is believed to contribute geochemically significant amounts of minerals that are deposited in the western part of the Pacific Ocean. These minerals may alter the oceanic primary productivity (Zhang et al., 2003; Zhuang et al., 1992) as well.

Since natural dust links the biogeochemical cycle of land, atmosphere, and ocean, understanding the emission, evolution, and transport of dust is essential for further examining its impacts on the Earth's system. Numerical modeling is one of the most important approaches for systematically investigating dust. Many global models simulate dust emissions, transport, and depositions. Huneeus et al. (2011) conducted intercomparisons of 15 global models and reported their simulated aerosol optical depth (AOD) and Ångström exponent (AE) within a factor of 2 and the deposition and surface concentration within a factor of 10 with respect to observations, indicating significant variations among different models. Regional models usually represent dust by following the same coherent manner as global models. For example, the Weather Research and Forecasting model coupled with Chemistry (WRF-Chem) (Grell et al., 2005) coupled with the GOCART scheme (Ginoux et al., 2001) has been applied to simulate dust emission over central East Asia (Kumar et al., 2014), the United States (Zhao et al., 2010), and East Asia (Chen et al., 2013). The Sulfur Transport and dEposition Model (STEM) (Carmichael et al., 2003) used the COAMPS scheme (Liu and Westphal, 2001) and has been applied over East Asia (Tang et al., 2004). Regional models have fine spatiotemporal resolution and multiple physical parameterizations at the cost of intensive computation. As compared to global models, regional models may provide more realistic representations of the surface roughness, soil moisture, and contents and also allow comparable validation against surface observations (Darmenova and Sokolik, 2008).

The Community Multiscale Air Quality (CMAQ) model is a state-of-the-science model and has been applied in numerous regional modeling studies worldwide. Unlike other models, in which dust is usually treated as a unique aerosol, the CMAQ distributes dust particles into 19 aerosol species, such as inorganic aerosols and trace metals. This approach is consistent with the original design of the CMAQ as an air quality model, and it also provides a potential platform to examine the diversities of chemical and physical properties within dust particles. It enables the model to examine the mixing status and net effect of natural dust and anthropogenic aerosols on air quality and regional climate. The validation of the CMAQ performance is not well understood due to limited research efforts. Appel et al. (2013) conducted a full year simulation with CMAQ over the continental United States for 2006 and reported good agreement between simulations and observations, with the mean bias around $\pm 0.5 \mu \mathrm{g} \mathrm{m}^{-3}$ and $0.5-1.5 \mu \mathrm{g} \mathrm{m}^{-3}(\sim \pm 30 \%)$ for soil concentrations over western and eastern United States, respectively. But the CMAQ simulations over other regions underestimate dust emissions significantly. Fu et al. (2014) reported that the default dust scheme in the CMAQ underestimated dust emission by $98 \%$ during a 6-day dust storm episode in 2011. With the modeling domain covering the entire Northern Hemisphere, Xing et al. (2015) also suggested that the CMAQ underestimated AOD by $30-60 \%$ in areas where dust is dominant, while the bias was less than $\pm 15 \%$ elsewhere.

The studies mentioned above indicate that the capability of the CMAQ to simulate natural dust emissions remains poorly understood. In addition, the current dust scheme in the CMAQ does not include dust heterogeneous chemistry, while some studies have revealed the important impact of dust chemistry on ambient air pollutants with both measurement (Krueger et al., 2004; Matsuki et al., 2005; Usher et al., 2003) and modeling evidence (Bauer et al., 2004; Bian and Zender, 2003; Dentener et al., 1996). The objective of this study is to evaluate and improve the model's capability to reproduce dust emission and also to enable the model to treat the dust heterogeneous chemistry. Section 2 introduces the method of applying new parameterizations and implementing dust heterogeneous chemistry in the CMAQ, whereas Sect. 3 summarizes the improved model performance. Section 4 discusses the enhanced model capability and remaining uncertainties, and Sect. 5 concludes the paper with a summary of the findings. 


\section{Methodology}

\subsection{Improvement of the CMAQ wind-blown dust emission module}

The process of wind-blown dust emission is controlled by a number of environmental variables, including wind speed, soil texture, land use type, vegetation cover, and soil moisture. Dust deflation is favored by dry soil with low and sparse vegetation and constrained by high soil moisture. The dust emission scheme employed in the CMAQ is developed by Tong et al. (2016). The emission (vertical flux) of the dust $F\left(\mathrm{~g} \mathrm{~m}^{-2} \mathrm{~s}^{-1}\right)$ was estimated based on a modified Owen's equation (Owen, 1964):

$$
\begin{aligned}
F= & \sum_{i=1}^{M} \sum_{j=1}^{N} K \times A \times \frac{\rho}{g} \times S_{i} \times \operatorname{SEP} \times u_{*} \times\left(u_{*}^{2}-u_{* t i, j}^{2}\right) \\
& \text { for } u_{*}>u_{* t i, j},
\end{aligned}
$$

where $M$ is the erodible land use type, $N$ is the soil texture type, and $K$ is the ratio of vertical to horizontal flux calculated based on the amount of clay (clay \%) within the soil:

$K=\left\{\begin{array}{l}10^{0.134 \times(\text { clay } \%)-6}, \text { when:clay } \%<20 \% \\ 0.0002, \text { when:clay } \%>20 \%\end{array}\right.$.

The value of $K(0.0002)$ for clay percentage $>20 \%$ is used here following the recommendation of Marticorena and Bergametti (1995). $A$ is a scaling factor (set as 32.0 in this study), $\rho$ is air density, $g$ is gravitational acceleration $\left(9.8 \mathrm{~m} \mathrm{~s}^{-2}\right), S_{i}$ is dust source area for land type $i$, and SEP is the soil erodibility factor, which is calculated based on the fraction of clay, silt, and sand of the soil as

$\mathrm{SEP}=0.08 \times$ clay $+1.0 \times$ silt $+0.12 \times$ sand.

$u_{*}$ is the friction velocity, and $u_{* t i, j}$ is the threshold friction velocity for soil type $j$ and land use type $i$. More details of the dust emission algorithm have been given in Tong et al. (2016). Equation (1) is applied only when the modelcalculated friction velocity exceeds the designated threshold value. Therefore, the value of threshold friction velocity is critical to determine the onset and magnitude of dust emission in the CMAQ model.

In the CMAQ dust module, the threshold friction velocity is dynamically calculated based on the presence of nonerodible elements and the change in soil moisture (Tong et al., 2016). The effect of non-erodible elements is represented by wind energy partitioning following Marticorena et al. (1997). The effect of soil moisture on dust emission is implemented following a two-step approach proposed by Fécan et al. (1999). First, the maximum water holding capacity $\left(W_{\max }\right)$ for each soil type is determined based on the amount of clay in the soil:

$$
W_{\max }=(0.0014 \times \text { clay }+0.17) \times \text { clay } .
$$

Table 1. Value of the saturation soil moisture limit $\left(S_{1}\right)$.

\begin{tabular}{lccc}
\hline Land cover & Shrubland & $\begin{array}{c}\text { Mixed shrub/ } \\
\text { grass land }\end{array}$ & $\begin{array}{c}\text { Barren or sparsely } \\
\text { vegetated }\end{array}$ \\
\hline Soil type & & & \\
\hline Sand & 0.395 & 0.135 & 0.068 \\
Loamy sand & 0.410 & 0.150 & 0.075 \\
Sandy loam & 0.435 & 0.195 & 0.114 \\
Silt loam & 0.485 & 0.255 & 0.179 \\
Silt & 0.476 & 0.361 & 0.084 \\
Loam & 0.451 & 0.240 & 0.155 \\
Sandy clay loam & 0.420 & 0.255 & 0.175 \\
Silty clay loam & 0.477 & 0.322 & 0.218 \\
Clay loam & 0.476 & 0.325 & 0.250 \\
Sandy clay & 0.426 & 0.310 & 0.219 \\
Silty clay & 0.482 & 0.370 & 0.283 \\
Clay & 0.482 & 0.367 & 0.286 \\
\hline
\end{tabular}

In the case of soil moisture exceeding $W_{\max }$, the threshold friction velocity is then adjusted (Marticorena et al., 1997) as

$u_{* t i, j}=u_{* i i, j} \times Z_{i, j} \times f_{\text {soilm } i, j}$

where $u_{* c i, j}$ is the initial threshold friction velocity constant, and $Z_{i, j}$ is the surface roughness adjusting factor calculated with surface roughness length from the meteorology field, calculated as

$Z=\frac{C_{1}}{C_{1} \times \ln Z_{\mathrm{ruf}}-C_{2}}$.

The constants $C_{1}=32$ and $C_{2}=-5$ used in this equation are derived from field measurement data from Gillette et al. (1980) and the relationship between roughness length and friction velocity described in Marticorena et al. (1997).

And $f_{\text {soilm } i, j}$ is the moisture adjustment factor calculated using a revised Fécan formulation (Fécan et al., 1999):

$f_{\text {soilm } i, j}=\left\{\begin{array}{l}1.0, \text { for } S_{\mathrm{m}} \leq W_{\max } \\ \left(1.0+1.21 \times\left(S_{\mathrm{m}}-W_{\max }\right)^{0.68}\right)^{0.5}, \\ \text { for } W_{\max } \leq S_{\mathrm{m}}<S_{1}\end{array}\right.$,

where $S_{\mathrm{m}}$ is soil moisture and $S_{1}$ is the saturation soil moisture limit determined by soil textures. The values of $S_{1}$ are given by the North American Mesoscale (NAM) modeling system (Rogers et al., 2009), as summarized in Table 1.

Previously, the values of initial threshold friction velocity constant were taken from observed data from wind tunnel experiments conducted by Gillette and coworkers (Gillette et al., 1980, 1982). Fu et al. (2014) reported the $u_{* c i, j}$ used in the CMAQ has an average value of $0.7 \mathrm{~m} \mathrm{~s}^{-1}$ among all soil types, which is too high to generate enough dust particles over East Asia. Fu et al. (2014) used a fixed value of $0.3 \mathrm{~m} \mathrm{~s}^{-1}$ based on a study of local measurements in a northern desert in China (Li et al., 2007). Although this smaller threshold helps generate a higher production of dust emission during the 6-day simulation episode from 1 to 6 May 2011, 



Figure 1. (a) Land cover categories, (b) soil types, and (c) comparison of initial friction velocity threshold constants in default (blue markers) and revised (black markers) dust schemes for shrubland (top), mixed shrub- and grassland (middle), and barren or sparsely vegetated (bottom) land cover.

the arbitrarily designated threshold value for all land covers and soil categories prevents the model from reproducing spatial and temporal variations of dust emission. In this study, we have conducted a reanalysis of the field data (Gillette et al., 1980, 1982) and revised the threshold friction velocities through removing the double counting of soil moisture in the CMAQ dust emission modeling. In these field campaigns, some of these experiments were performed under rather dry conditions, but for other samples the effect of soil moisture cannot be ignored. Therefore, these values reported from field experiments are not always suitable for being used directly as the initial threshold friction velocity constant, which is assumed to represent extremely dry conditions. Meanwhile, in the CMAQ dust module, dynamic soil moisture data are used to adjust threshold friction velocity. Therefore, we need to convert the wet-condition data into threshold values under dry conditions. Otherwise, there will be the double counting of soil moisture in some cases.

We took a three-step approach to calibrate the threshold friction velocity. First, the value of soil moisture was extracted for each sample from the raw field dataset (courtesy from Dale Gillette, retired). Next, these data were used to feed the Fécan formula (Fécan et al., 1999) to derive the drycondition threshold velocity by casting soil moisture back to zero. We have reprocessed the data for the soil and land use types measured by Gillette $(1980,1982)$. In the case of missing data for certain soil types, we have chosen the values with the soil composition closest to a measured type following the USDA soil composition diagram (Fig. 1 of Gillette et al., 1980). Finally, the revised values of $u_{* c i, j}$ are implemented in the CMAQ. To our knowledge the double-counting issue affects the dust emission module in CMAQ only because the microphysical parameterization is developed based on Gillette et al. (1980) data. It also explains the significant underestimations of dusty by CMAQ as reported in Appel et al. (2013) and Fu et al. (2014). The comparison of the default and revised constants is summarized in Fig. 1c. As the double-count of soil moisture has been corrected, the revised constants are lower than the default ones. The majority of land cover in the Gobi is categorized as shrubland, where the revised initial threshold friction velocity constants are significantly lower than the default values for all soil types as shown in Fig. 1c, indicating that the revised scheme is expected to produce higher dust emissions over the Gobi. The Taklamakan Desert is mainly configured as barren or sparsely vegetated land cover with a sandy soil type, which only shows a small drop in the threshold friction velocity constant from 0.28 to $0.23 \mathrm{~m} \mathrm{~s}^{-1}$, indicating that the changes in dust emission over the Taklamakan may not be substantial. The CMAQ distributes dust emission to four size bins: $0.1-1.0,1.0-2.5$, 2.5-5.0, and 5.0-10.0 $\mu \mathrm{m}$, with the mass contribution as 3 , 17,41 , and $39 \%$ within each bin, respectively. The first two bins represent the fine-mode aerosol and the larger two rep- 
resent the coarse mode. So the mass contribution is $20 \%$ for fine-mode and $80 \%$ for coarse-mode aerosol.

\subsection{Implementing source-dependent speciation profile}

The emission of natural wind-blown dust particles is distributed to 19 aerosol species in the CMAQ, following the profile developed based on the EPA's SPECIATE database (Simon et al., 2010). As compared with other models that treat dust as a unique aerosol species, the CMAQ approach provides a more detailed description of dust mineralogy. This feature benefits CMAQ by enabling the model to maintain the consistency between dust and other types of existing aerosol in the modeling system. However, mass contributions of different chemical components may differ greatly among different source areas; thus, using a fixed profile for all dust sources may introduce uncertainty and lose the capacity to model the varieties of dust particles. The mass contribution of aluminum ( $\mathrm{Al}$ ) is around $5-8 \%$ for pure minerals around the world, and the ratios between other trace metals and Al may vary substantially for different dust particles. Thus, the elemental mass ratio between calcium and aluminum $(\mathrm{Ca} / \mathrm{Al})$ is usually used to identify the source of dust samples (Huang et al., 2010; Sun et al., 2005). For example, the $\mathrm{Ca} / \mathrm{Al}$ ratio for Saharan dust is around 0.9 and 1.0 for fine and coarse dust particles, respectively (Blanco et al., 2003; Formenti et al., 2003; Kandler et al., 2007; Reid et al., 2003); for Arabian dust, it is around 0.13 and 0.15 for coastal and inland dust, respectively (Krueger et al., 2004); for Taklamakan dust, it is about 1.5-1.9 (Huang et al., 2010); and for dust from the Gobi Desert, it is 0.4-1.1 (Arimoto et al., 2006; Zhang et al., 2003). To characterize the dust aerosols in the CMAQ better, source-dependent speciation profiles are developed in this study for the Gobi and Taklamakan deserts based on local measurement data collected by Huang et al. (2010). These two profiles are compared with the default one in the CMAQ as shown in Table 2. For the model species which are not measured in Huang et al. (2010), including primary organic carbons (APOC), noncarbon aerosols (APNCOM), elementary carbons (EC), silicon (ASI), and water (AH2O), their values for the Taklamakan and Gobi are kept the same as in the default profile. And for unspeciated (AOTHR) and non-anion dust (ASOIL), their values in the two new profiles are calculated based on the contributions of all other species, to keep the total mass contributions conservative. It is important to note that the model species refer to an anion or cation phase for sulfate ( $\left.\mathrm{ASO} 4, \mathrm{SO}_{4}^{2-}\right)$, nitrate $\left(\mathrm{ANO} 3, \mathrm{NO}_{3}^{-}\right)$, chloride ( $\mathrm{ACL}$, $\mathrm{Cl}^{-}$), ammonium (ANH4, $\mathrm{NH}_{4}^{+}$), sodium (ANA, $\left.\mathrm{Na}^{+}\right), \mathrm{Ca}_{2}^{+}$ (ACA), magnesium (AMG, $\mathrm{Mg}_{2}^{+}$), and potassium (AK, $K^{+}$) and an element phase for iron (AFE, Fe), $\mathrm{Al}(\mathrm{AAL})$, silicon (ASI, Si), titanium (ATI, Ti), and manganese (AMN, Mn). Mass contributions of different aerosols differ significantly among the profiles as shown in Table 2. For example, $\mathrm{Ca}_{2}^{+}$accounts for $7.94 \%$ of the total fine-particle mass in the default profile, which is much higher than the Taklamakan $(2.063 \%)$ and the Gobi (1.788\%). For $\mathrm{Mg}_{2}^{+}$, the default profile assumes $0 \%$ of mass contribution, yet the values for the Taklamakan and Gobi are 0.165 and $0.799 \%$, respectively. The $K^{+}$contribution within the default profile is $3.77 \%$, while for the Taklamakan it is $0.153 \%$ and for the Gobi it is $0.282 \%$. Si is one of the most abundant metals in the crust, yet the default speciation profile has an inappropriate assumption of zero $\mathrm{Si}$ content in coarse-mode dust particles. As no measurements are found for Si over the Taklamakan or Gobi, we use the element ratio of $\mathrm{Al} / \mathrm{Si}$ as $8 \% / 28 \%$ to derive the mass contribution of $\mathrm{Si}$ in the coarse model, which is a conventional approach for trace metal analysis (Huang et al., 2010). Different configurations within the speciation profile will lead to significant differences in model predictions for these trace metals, demonstrated in more detail in Sect. 3.

\subsection{Implementation of heterogeneous reactions}

The default heterogeneous chemistry scheme within the CMAQ considered the conversions from $\mathrm{N}_{2} \mathrm{O}_{5}$ to $\mathrm{HNO}_{3}$ and from $\mathrm{NO}_{2}$ to $\mathrm{HONO}$ and $\mathrm{HNO}_{3}$. These reactions play an important role in the nighttime production of nitrate aerosols (Dong et al., 2014; Pathak et al., 2011; Pun and Seigneur, 2001). Heterogeneous reactions are treated as irreversible in the model (Davis et al., 2008; Sarwar et al., 2008; Vogel et al., 2003). While dust particles serve as a platform for heterogeneous reaction, they also participate in some of the reactions to take up the gas-phase species. The uptake of gases onto the surface of dust particles is defined by a pseudo-first-order reaction rate $K$ (Dentener et al., 1996; Heikes and Thompson, 1983) calculated as

$K=\left(\frac{r_{\mathrm{p}}}{D_{\mathrm{g}}}+\frac{4}{v_{\mathrm{g}} \gamma_{\mathrm{g}}}\right)^{-1} A_{\mathrm{p}}$,

where $r_{\mathrm{p}}$ is the radius of the particle, $D_{\mathrm{g}}$ is the diffusion coefficient of gas molecules, $v_{\mathrm{g}}$ is the mean molecular velocity of gas, $A_{\mathrm{p}}$ is the surface area of the particle, and $\gamma_{\mathrm{g}}$ is the uptake coefficient for gas. Many research efforts have been devoted to quantifying the uptake coefficients. The reported values of the uptake coefficient may differ by more than $2-3$ orders of magnitude, depending on the source of the dust samples and analytical methods (Cwiertny et al., 2008; Usher et al., 2003). While this work focuses on East Asia, the uptake coefficients are mainly collected from Zhu et al. (2010), which summarized the estimations for dust samples from deserts in China. The "best guess" regarding uptake coefficients was suggested based on the analysis of different measurement studies summarized in Zhu and Zhang (2010). But in this study both the lower and upper limits of uptake coefficients are examined to evaluate their impacts. Table 3 lists the 13 dust heterogeneous reactions implemented in the CMAQ in this study, with the lower and upper boundaries of uptake coefficients. 
Table 2. Dust emission speciation profiles from the default CMAQ, and the profiles derived in this study for the Taklamakan and Gobi deserts.

\begin{tabular}{|c|c|c|c|c|c|c|c|}
\hline \multirow[t]{3}{*}{ Model species } & \multirow[t]{3}{*}{ Description } & \multicolumn{6}{|c|}{ Mass contributions (\%) } \\
\hline & & \multicolumn{3}{|c|}{ Fine mode ( $\mathrm{I}, \mathrm{J}$ mode in $\mathrm{CMAQ} \leq 2.5 \mu \mathrm{m})$} & \multicolumn{3}{|c|}{ Coarse mode $(\mathrm{K}$ mode in $\mathrm{CMAQ} \leq 10 \mu \mathrm{m})$} \\
\hline & & Default & Taklamakan & Gobi & Default & Taklamakan & Gobi \\
\hline ASO4 & Sulfate $\left(\mathrm{SO}_{4}^{2-}\right)$ & 2.5 & 3.554 & 0.953 & 2.655 & 2.825 & 0.471 \\
\hline ANO3 & Nitrate $\left(\mathrm{NO}_{3}^{-}\right)$ & 0.02 & 0.181 & 0.204 & 0.16 & 0.125 & 0.084 \\
\hline $\mathrm{ACL}$ & Chloride $\left(\mathrm{Cl}^{-}\right)$ & 0.945 & 2.419 & 0.544 & 1.19 & 2.357 & 0.094 \\
\hline ANH4 & Ammonium $\left(\mathrm{NH}_{4}^{+}\right)$ & 0.005 & 0.098 & 0.346 & 0 & 0.066 & 0.185 \\
\hline ANA & Sodium $\left(\mathrm{Na}^{+}\right)$ & 3.935 & 2.234 & 1.016 & 0 & 2.056 & 0.301 \\
\hline ACA & Calcium $\left(\mathrm{Ca}_{2}^{+}\right)$ & 7.94 & 2.063 & 1.788 & 0 & 1.423 & 1.082 \\
\hline AMG & Magnesium $\left(\mathrm{Mg}_{2}^{+}\right)$ & 0 & 0.165 & 0.799 & 0 & 0.121 & 0.819 \\
\hline AK & Potassium $\left(K^{+}\right)^{-}$ & 3.77 & 0.153 & 0.282 & 0 & 0.108 & 0.121 \\
\hline APOC & Primary organic carbon & 1.075 & 1.075 & 1.075 & 0 & 0 & 0 \\
\hline APNCOM & Non-carbon organic matter & 0.43 & 0.43 & 0.43 & 0 & 0 & 0 \\
\hline AEC & Elementary carbon & 0 & 0 & 0 & 0 & 0 & 0 \\
\hline AFE & Iron $(\mathrm{Fe})$ & 3.355 & 4.689 & 2.425 & 0 & 3.75 & 3.055 \\
\hline AAL & Aluminum (Al) & 5.695 & 5.926 & 4.265 & 0 & 4.987 & 4.641 \\
\hline ASI & Silicon $(\mathrm{Si})$ & 19.425 & 20.739 & 14.929 & 0 & 17.454 & 16.245 \\
\hline ATI & Titanium (Ti) & 0.28 & 0.312 & 0.337 & 0 & 0.285 & 0.365 \\
\hline $\mathrm{AMN}$ & Manganese (Mn) & 0.115 & 0.0758 & 0.063 & 0 & 0.062 & 0.072 \\
\hline $\mathrm{AH} 2 \mathrm{O}$ & Water $\left(\mathrm{H}_{2} \mathrm{O}\right)$ & 0.541 & 0.541 & 0.541 & 0 & 0 & 0 \\
\hline AOTHR & Unspeciated & 50.219 & 55.345 & 70.002 & 0 & 0 & 0 \\
\hline ASOIL & Non-anion dust & 0 & 0 & 0 & 95.995 & 64.382 & 72.464 \\
\hline
\end{tabular}

\subsection{Model inputs, configuration, and simulation scenarios}

The CMAQ model simulation uses version 5.0.1. In this study, the CMAQ is configured with the updated 2005 carbon bond gas-phase mechanism (CB05), aerosol module AE6, inline photolysis calculation and $\mathrm{NO}$ emission from lightning, and the Euler backward iterative (EBI) solver. The modeling domain covers East Asia and peninsular Southeast Asia as shown in Fig. 2. The CMAQ simulation is performed with a $36 \mathrm{~km}$ horizontal grid spacing and 34 vertical layers with a model top at $50 \mathrm{hPa}$ and finer resolution at the near-surface layers to represent the planetary boundary layer clearly. The simulation period covers March and April from 2006 to 2010 to represent the spring dust episode of East Asia.

The meteorology field is simulated with the Weather Research and Forecasting model (WRFv3.4, Skamarock et al., 2008). Initial and boundary conditions are downscaled from the GEOS-Chem global model simulation for 2006-2010 by following the routines described in Lam and Fu (2009). Biogenic emission is from MEGAN2.1 (Guenther et al., 2006; Müller et al., 2008), biomass burning emission is from FLAMBE (Reid et al., 2009), and anthropogenic emission is from Zhao et al. (2013) over China and INTEX-B over other countries within the domain. More details about meteorology and emission datasets are given in Dong and Fu (2015a, b).

To examine the performance of the CMAQ model development with revised parameterization and dust heterogeneous reactions, a total of six scenarios is conducted as listed in

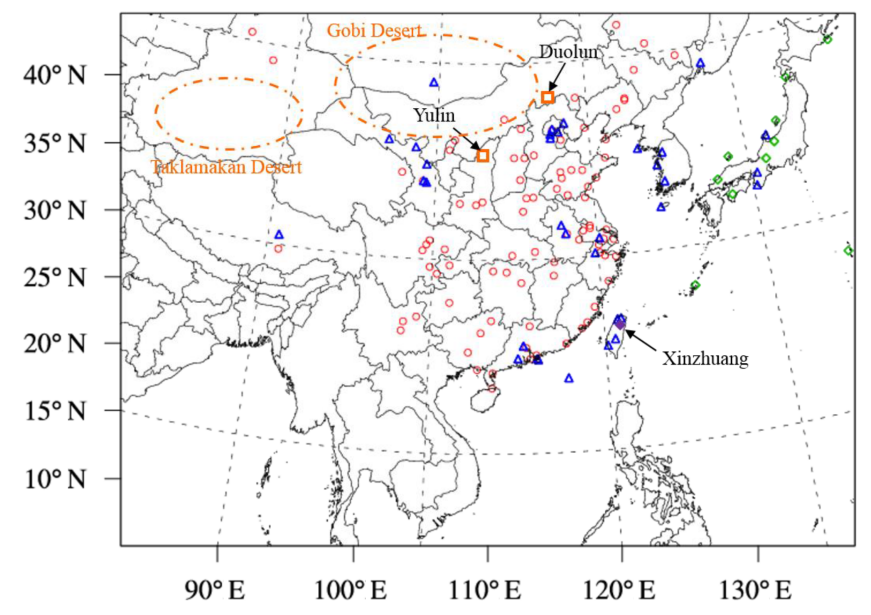

Figure 2. Modeling domain and locations of observation stations from Fudan observation network (orange rectangles), API (red circles), AERONET (AErosol RObotic NETwork; blue triangles), EANET (green diamonds), and TAQMN (purple diamonds) over East Asia.

Table 4. The simulations Dust_Off and Dust_Default are designed to investigate the performance of the CMAQ without dust emission and with the default dust plume rise scheme; Dust_Revised is designed to investigate the performance of applying the new parameterization of initial friction velocity threshold constants; Dust_Profile is designed to examine the improvement by applying source-dependent dust com- 
Table 3. Heterogeneous reactions and uptake coefficients.

\begin{tabular}{|c|c|c|c|}
\hline No. & Reaction & Uptake coefficient & References \\
\hline \multicolumn{4}{|c|}{ Default heterogeneous reactions in CMAQv5.0.1 } \\
\hline $\mathrm{C} 1$ & $\mathrm{~N}_{2} \mathrm{O}_{5}+\mathrm{H}_{2} \mathrm{O} \rightarrow 2 \mathrm{HNO}_{3}$ & $\begin{array}{l}\gamma=\left\{\begin{array}{l}\left(x_{1}+x_{2}\right) \times \gamma_{\mathrm{d}}^{*}+x_{3} \times \min \left(\gamma_{\mathrm{d}}^{*}, \gamma_{3}\right), \mathrm{RH}<\mathrm{CRH} \\
\sum_{i=1}^{3} x_{i} \times \gamma_{i}^{*}, \mathrm{RH}>\mathrm{IRH}, \\
0.02, \text { otherwise }\end{array}\right. \\
\text { where } x_{1}, x_{2} \text {, and } x_{3} \text { and } \gamma_{1}, \gamma_{2} \text {, and } \gamma_{3} \text { are the normalized molar con- } \\
\text { centrations and } \mathrm{N}_{2} \mathrm{O}_{5} \text { uptake coefficients on } \mathrm{NH}_{4} \mathrm{HSO}_{4},\left(\mathrm{NH}_{4}\right)_{2} \mathrm{SO}_{4} \text {, } \\
\text { and } \mathrm{NH}_{4} \mathrm{NO}_{3} \text { respectively, } \gamma_{\mathrm{d}}^{*}=\min \left(\gamma_{\mathrm{d}}, 0.0124\right) \text {, where } \gamma_{\mathrm{d}} \text { is the up- } \\
\text { take coefficient on dry particles determined by relative humidity and } \\
\text { temperature, } \mathrm{RH} \text { is relative humidity, CRH is crystallization relative } \\
\text { humidity, IRH is ice formation relative humidity determined by tem- } \\
\text { perature }\end{array}$ & Davis et al. (2008) \\
\hline $\mathrm{C} 2$ & $2 \mathrm{NO}_{2}+\mathrm{H}_{2} \mathrm{O} \rightarrow \mathrm{HONO}+\mathrm{HNO}_{3}$ & $K=5.0 \times 10^{-6} \times A_{\mathrm{p}}$ & Vogel et al. (2003) \\
\hline \multicolumn{4}{|c|}{ Implemented dust heterogeneous reactions in this work } \\
\hline $\mathrm{R} 1$ & $\mathrm{O}_{3}+$ dust $\rightarrow$ products & $5.0 \times 10^{-5} \sim 1.0 \times 10^{-4}$ & Zhu et al. (2010) \\
\hline R2 & $\mathrm{OH}+$ dust $\rightarrow$ products & $0.1 \sim 1.0$ & Zhu and Zhang (2010) \\
\hline R3 & $\mathrm{H}_{2} \mathrm{O}_{2}+$ dust $\rightarrow$ products & $1.0 \times 10^{-4} \sim 2.0 \times 10^{-3}$ & Zhu and Zhang (2010) \\
\hline $\mathrm{R} 4$ & $\mathrm{CH}_{3} \mathrm{COOH}+$ dust $\rightarrow$ products & $1.0 \times 10^{-3}$ & Zhu and Zhang (2010) \\
\hline R5 & $\mathrm{CH}_{3} \mathrm{OH}+$ dust $\rightarrow$ products & $1.0 \times 10^{-5}$ & Zhu and Zhang (2010) \\
\hline R6 & $\mathrm{CH}_{2} \mathrm{O}+$ dust $\rightarrow$ products & $1.0 \times 10^{-5}$ & Zhu and Zhang (2010) \\
\hline R7 & $\mathrm{HNO}_{3}+$ dust $\rightarrow 0.5 \mathrm{NO}_{3}^{-}+0.5 \mathrm{NO}_{x}$ & $1.1 \times 10^{-3} \sim 0.2$ & Dentener et al. (1996) \\
\hline $\mathrm{R} 8$ & $\mathrm{~N}_{2} \mathrm{O}_{5}+$ dust $\rightarrow 2 \mathrm{NO}_{3}^{-}$ & $1.0 \times 10^{-3} \sim 0.1$ & Zhu and Zhang (2010) \\
\hline R9 & $\mathrm{NO}_{2}+$ dust $\rightarrow \mathrm{NO}_{3}^{-}$ & $4.4 \times 10^{-5} \sim 2.0 \times 10^{-4}$ & Underwood et al. (2001) \\
\hline $\mathrm{R} 10$ & $\mathrm{NO}_{3}+$ dust $\rightarrow \mathrm{NO}_{3}^{-}$ & $0.1-0.23$ & Underwood et al. (2001) \\
\hline $\mathrm{R} 11$ & $\mathrm{NO}_{3}+$ dust $\rightarrow \mathrm{HNO}_{3}$ & $1.0 \times 10^{-3}$ & Martin et al. (2003) \\
\hline $\mathrm{R} 12$ & $\mathrm{HO}_{2}+$ dust $\rightarrow 0.5 \mathrm{H}_{2} \mathrm{O}_{2}$ & 0.2 & Zhu and Zhang (2010) \\
\hline $\mathrm{R} 13$ & $\mathrm{SO}_{2}+$ dust $\rightarrow \mathrm{SO}_{4}^{2-}$ & $1.0 \times 10^{-4} \sim 2.6 \times 10^{-4}$ & Phadnis and Carmichael (2000) \\
\hline
\end{tabular}

Table 4. Simulation design.

\begin{tabular}{ll}
\hline Scenario & Configuration of CMAQv5.0.1 \\
Dust_Off & Without in-line calculation of dust \\
Dust_Default & With default dust plume rise scheme \\
Dust_Revised & Revised initial friction velocity threshold constant in dust plume rise scheme \\
Dust_Profile & Same as Dust_Revised but with implemented source-dependent speciation profile \\
Dust_Chem & Same as Dust_Profile but with implemented dust chemistry with lower limit of uptake coefficient \\
Dust_ChemHigh & Same as Dust_Chem but with upper limit of uptake coefficients \\
\hline
\end{tabular}

position profiles; and Dust_Chem and Dust_ChemHigh are designed to examine the impacts of implementing heterogeneous chemistry with the lower and upper estimations of uptake coefficients, respectively. The scenario Dust_Profile, Dust_Chem, and Dust_ChemHigh are all performed based on Dust_Revised.

\subsection{Observations}

Both ground-based measurements and satellite observations are used in this study to help examine the uncertainty and evaluate the performance of the model. The Air Pollution Index (API, http://datacenter.mep.gov.cn) reported by the Chinese Ministry of Environmental Protection (MEP) is used to evaluate the $\mathrm{PM}_{10}$ predictions from the CMAQ. The API is reported on a daily basis with a national coverage of 86 middle size or larger cities in China and has been applied in many modeling studies for evaluation purposes (Zhao et al., 2013). To investigate the transport of dust particles over downwind areas simulated by the model, we also used surface observations from the Acid Deposition Monitoring Network in East Asia (EANET; EANET, 2007) over Japan, and observations from the Taiwan Air Quality Monitoring Network (TAQMN; http://taqm.epa.gov.tw/taqm/en/default. aspx). EANET provides hourly or daily records of $\mathrm{PM}_{10}, \mathrm{O}_{3}$, $\mathrm{NO}_{x}$, and $\mathrm{SO}_{2}$ and also biweekly (or longer-interval) records of $\mathrm{HNO}_{3}, \mathrm{SO}_{4}^{2-}$, and $\mathrm{NO}_{3}^{-}$. Data from EANET is also employed in this study for examining model performance with dust heterogeneous chemistry. The TAQMN provides observations of most criteria air pollutants, yet only $\mathrm{PM}_{10}$ observations at the Xinzhuang site are used in this study to focus on dust storm impact. These variables are used to exam- 
ine the simulation responses by implementing dust heterogeneous chemistry. Ground-based measurements of $\mathrm{K}^{+}, \mathrm{Mg}_{2}^{+}$, $\mathrm{Ca}_{2}^{+}$, and $\mathrm{PM}_{2.5}$ at Duolun and Yunlin from Fudan University's observation network (Huang et al., 2010) are used to investigate the model's capability to simulate tracer metals by applying the source-dependent speciation profile for suspended dust particles. AOD from the AErosol RObotic NETwork (AERONET; http://aeronet.gsfc.nasa.gov/) operated by NASA is also collected to evaluate the CMAQ predictions. To examine the spatial distribution and column density of model-simulated dust particles, we also used AOD products from the Moderate Resolution Imaging Spectroradiometer (MODIS; http://modis.gsfc.nasa.gov/). All observations are collected for the period of March and April from 2006 to 2010, except for the Fudan University data, which only cover March and April in 2007. The locations of API, EANET, TAQMN, and AERONET observational stations are indicated in Fig. 2, along with the locations of Duolun and Yunlin. Table 5 summarizes detailed information on each observation network.

\section{Results}

\subsection{Improved model performance with revised friction velocity thresholds}

To examine model improvement by implementing new initial threshold friction velocity constants, simulation results from Dust_Default and Dust_Revised are compared for the spatial distribution of $\mathrm{PM}_{10}$ and evaluation bias against API. Dust_Default - Dust_Off and Dust_Revised - Dust_Off represent the $\mathrm{PM}_{10}$ from the default dust scheme and the revised dust scheme, respectively, as shown in Fig. 3a and b. $\mathrm{PM}_{10}$ concentrations generated from dust are averaged for March and April from 2006 to 2010. Figure 3a indicates that the default dust scheme produces a very limited amount of $\mathrm{PM}_{10}$ only over the Gobi Desert (less than $70 \mu \mathrm{g} \mathrm{m}^{-3}$ ), which can hardly represent the East Asian dust storms. The revised scheme produces higher $\mathrm{PM}_{10}$ concentrations of more than $400 \mu \mathrm{g} \mathrm{m}^{-3}$ in the Gobi source region, as shown in Fig. 3b. Dust plumes are generated by the revised model over the Gobi and Taklamakan deserts and also in sparse grassland over the northwest region of the Tibetan Plateau. Particles from dust plumes are transported southeastward and contribute $50-100 \mu \mathrm{g} \mathrm{m}^{-3}$ of $\mathrm{PM}_{10}$ over northern and eastern China and less than $50 \mu \mathrm{g} \mathrm{m}^{-3}$ over southern China, South Korea, and Japan. Huang et al. (2010) demonstrated that there are two transport pathways for Asian dust: plumes from the Gobi and Taklamakan are either pushed by prevailing winds eastward towards South Korea and Japan or southeastward down towards southern China and Taiwan. With the revised dust scheme, the CMAQ generally reproduces the spatial distribution of Asian dust as shown in Fig. 3b, which indicates the most significant impact over northern and east-

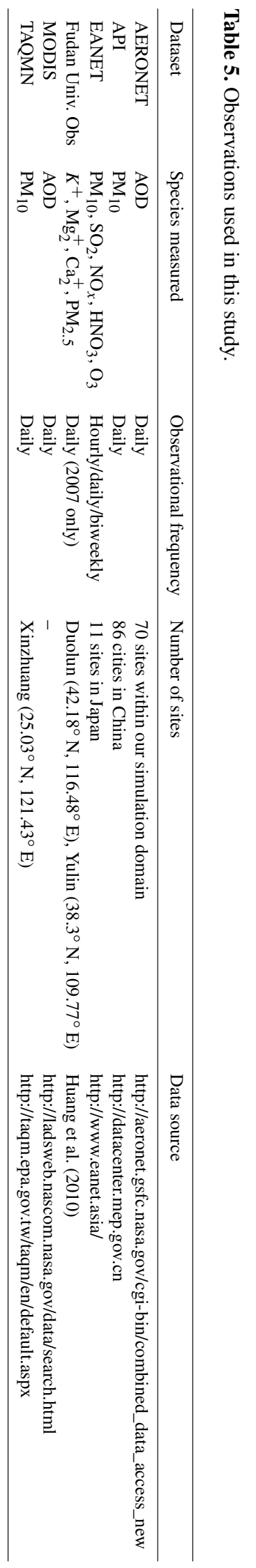

www.atmos-chem-phys.net/16/8157/2016/ 
Dust_Default

(a)

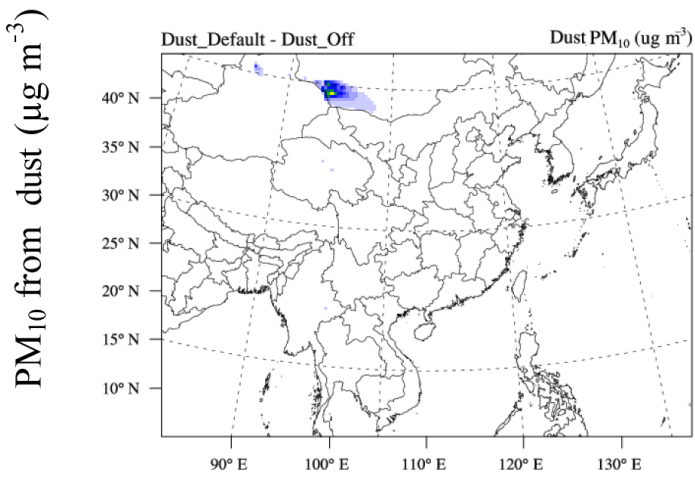

(c)

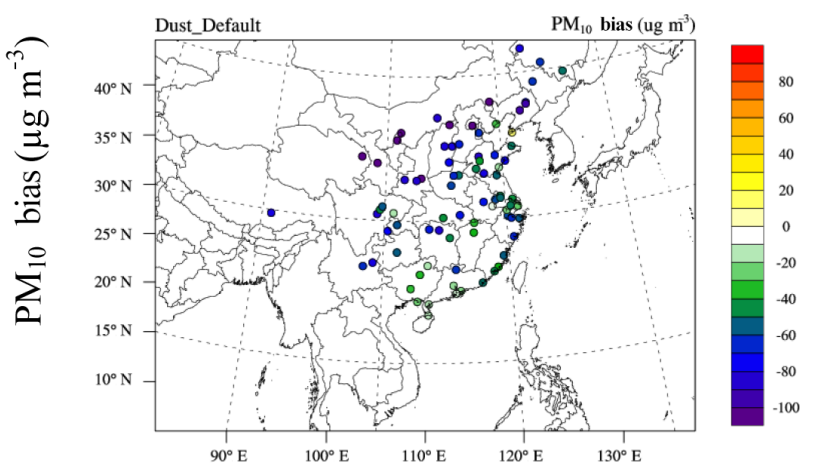

Dust Revised

(b)

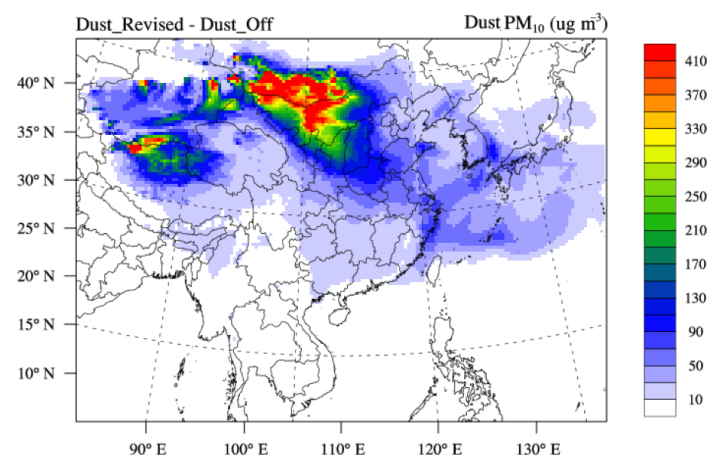

(d)



Figure 3. Five-year averages of $\mathrm{PM}_{10}$ concentration difference from (a) Dust_Default - Dust_Off and (b) Dust_Revised - Dust_Off. PM 10 simulation bias against observation at API stations for (c) Dust_Default and (d) Dust_Revised scenarios.

ern China and relatively weak impacts over downwind areas along the transport pathway towards the southeast. Figure $3 \mathrm{c}$ and d demonstrate the evaluation bias at the API cities over China for the Dust_Default and Dust_Revised scenarios, respectively. With the default dust scheme, the CMAQ shows a large negative bias for the entire domain. The most serious underestimation is found over northern and western China, with a negative bias of more than $-80 \mu \mathrm{g} \mathrm{m}^{-3}$. Figure $3 \mathrm{c}$ also suggests that cities closer to the Taklamakan and Gobi deserts have a larger negative bias, indicating that the default scheme cannot generate sufficient dust emission to reproduce the observed $\mathrm{PM}_{10}$. With the revised scheme as shown in Fig. 3d, simulation biases for most of the cities are reduced down to $\pm 20 \mu \mathrm{g} \mathrm{m}^{-3}$. The largest overestimation is found at Hohhot $\left(39 \mathrm{\mu g} \mathrm{m}^{-3}\right)$, and the largest underestimation is found at Xining and Lanzhou $\left(-60 \mu \mathrm{g} \mathrm{m}^{-3}\right)$. Figure $3 \mathrm{~d}$ also indicates that the model tends to have a larger simulation discrepancy in cities close to the desert.

Figure 4a to c summarize the evaluation statistics for simulated $\mathrm{PM}_{10}$ against observations from the API. Daily data pairs from observation and simulation are used here to calculate the statistics. The Dust_Off scenario underestimates $\mathrm{PM}_{10}$ concentration by $-56.74 \%$. Since dust storms from the Taklamakan and Gobi substantially contribute to suspended particle concentrations over East Asia during spring, a simulation with no dust emission should be responsible for the large underestimation. With the default dust emission module, model performance for the scenario Dust_Default is only slightly improved and $\mathrm{PM}_{10}$ is still underestimated by $-55.42 \%$, as shown by Fig. $4 \mathrm{~b}$. The comparison between Dust_Off and Dust_Default suggests that the default dust module is not able to generate sufficient elevated particles to match the observed $\mathrm{PM}_{10}$ levels from the API. On the other hand, the Dust_Revised scenario shows a much better performance with an normalized mean bias (NMB) value of $-16.06 \%$, as shown in Fig. 4c. Simulation results are also evaluated against AOD observations from the AERONET, with the statistics shown in Fig. $4 d$ to f. Statistics for AOD evaluation against the AERONET suggest similar model performances as for $\mathrm{PM}_{10}$. The CMAQ simulation without dust 
(a) Dust_Off

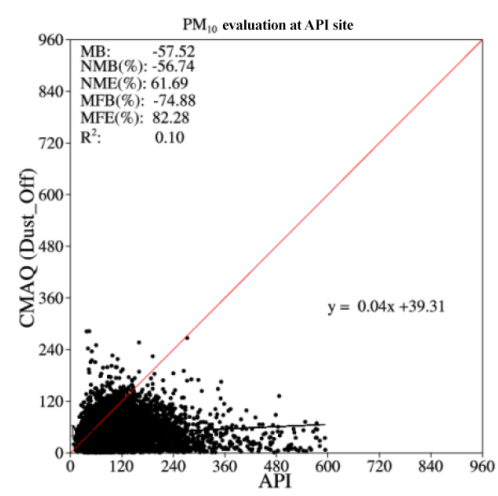

(d) Dust_Off

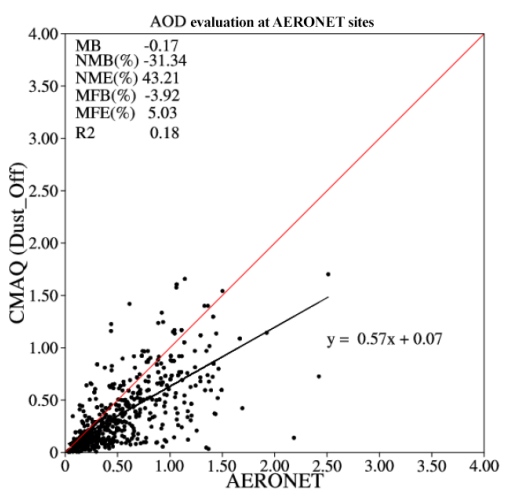

(b) Dust_Default

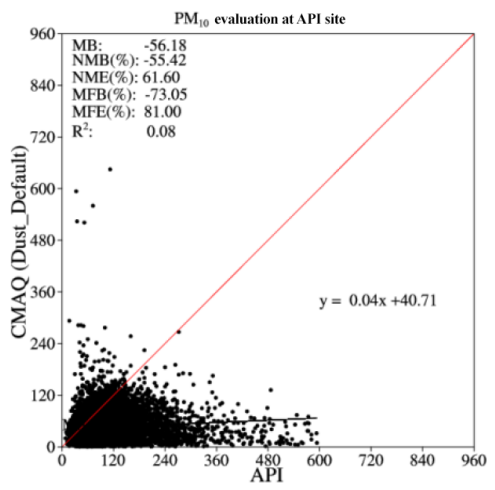

(e) Dust_Default

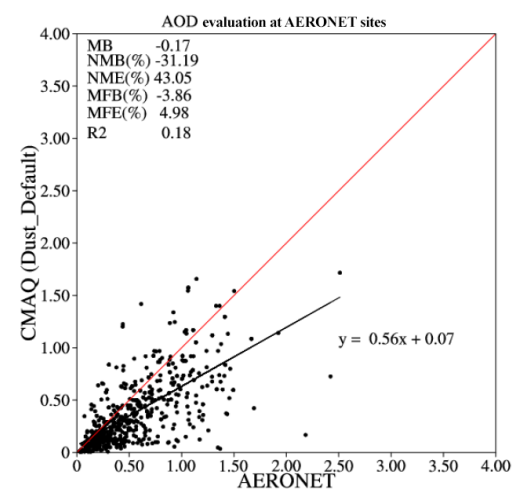

(c) Dust_Revised

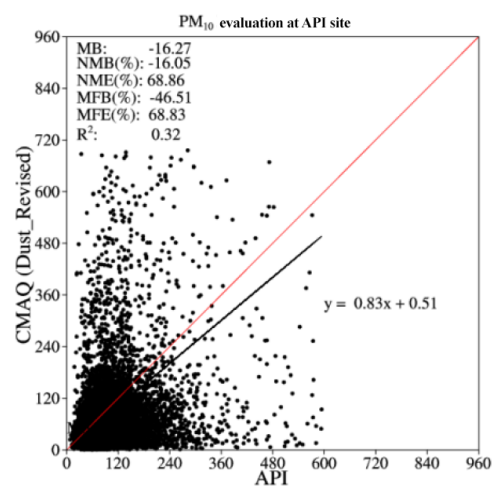

(f) Dust_Revised



Figure 4. CMAQ evaluation against $\mathrm{PM}_{10}$ from API (upper row) and AOD (bottom row) from AERONET for Dust_Off (left column), Dust_Default (middle column), and Dust_Revised (right column) scenarios. The formula for calculating evaluation statistics, including mean bias (MB), normalized mean bias (NMB), normalized mean error (NME), mean fractional bias (MFB), mean fractional error (MFE), and correlation coefficient $(R)$, can be found in Dong et al. (2013).

rise underestimates AOD by $-31.34 \%$ at AERONET stations, and the default dust module offers almost no improvement for AOD prediction. The Dust_Revised scenario underestimates AOD by $-22.1 \%$, indicating that the revised scheme is also able to improve the model performance for simulating fine-mode dust.

\subsection{Impacts of applying source-dependent profile}

The speciation of dust particles determines the contributions of crust species and trace metal concentrations predicted by the model. As described in Sect. 2.2, we modified the fixed speciation profile within the CMAQ to be source-dependent for the Gobi and Taklamakan, and in this section groundbased observations collected at Duolun and Yulin are used to investigate the impacts by applying different speciation profiles. The model simulations from the Dust_Revised and Dust_Profile scenarios are compared with observations for $K^{+}, \mathrm{Mg}_{2}^{+}$, and $\mathrm{Ca}_{2}^{+}$with data pairs, as shown in Fig. 5 (sim- ulations and observations for $K^{+}$and $\mathrm{Mg}_{2}^{+}$are upscaled by 5 and 10 time, respectively, to make them comparable with $\mathrm{Ca}_{2}^{+}$in the same figure), and evaluation statistics are summarized in Table 6. The two cities are close to the Gobi Desert, as shown by Fig. 2. Huang et al. (2010) used back trajectory and $\mathrm{Ca} / \mathrm{Al}$ ratio analysis to demonstrate that the Gobi Desert is the main contributor of dust particles at Duolun and Yulin. Figure 5a indicates that with the default speciation profile, the CMAQ overestimates $K^{+}$and $\mathrm{Ca}_{2}^{+}$by 208.9 and $36.69 \%$, respectively. Predicted $\mathrm{Mg}_{2}^{+}$concentration is almost zero because there is no emission of $\mathrm{Mg}_{2}^{+}$in the anthropogenic emission inventories, and the default profile indicated a $0 \%$ mass contribution of $\mathrm{Mg}_{2}^{+}$from dust emission. With the source-dependent speciation profile, the CMAQ simulation of $\mathrm{Mg}_{2}^{+}$is increased significantly as shown in Fig. 5b. The revised CMAQ underestimates $K^{+}$and $\mathrm{Ca}_{2}^{+}$by -47.83 and $-53.12 \%$, respectively. A consistent negative bias for trace metals should be due to the underestimation of total finemode aerosol within dust. Figure 5c shows the compari- 
(a) Dust_Revised

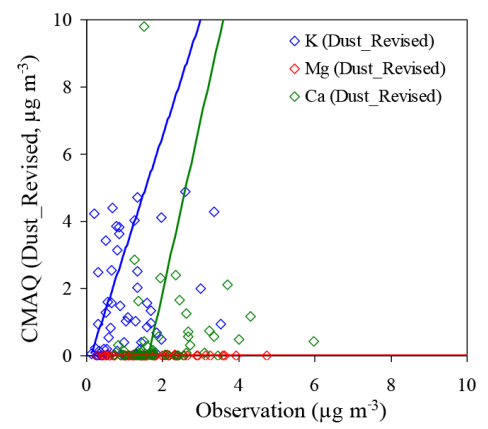

(b) Dust_Profile

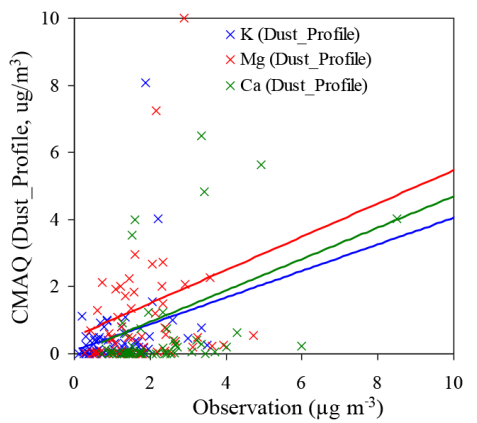

(c) $\mathrm{PM}_{2.5}$

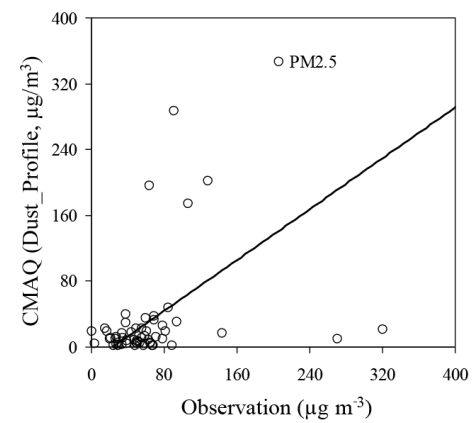

Figure 5. Model evaluations of CMAQ-simulated metal tracers against observations from Fudan University (shown in Table 5) at Duolun and Yulin for (a) Dust_Revised and (b) Dust_Profile scenarios. Evaluation statistics are shown in Table 6. Note that simulations and observations of $\mathrm{K}^{+}$and $\mathrm{Mg}_{2}^{+}$are upscaled by 5 and 10 times, respectively, to make them comparable with $\mathrm{Ca}_{2}^{+}$in the same plot. (c) The evaluation of CMAQ-simulated $\mathrm{PM}_{2.5}$ at Duolun and Yulin.

Table 6. Evaluation statistics for tracer metals and $\mathrm{PM}_{2.5}$.

\begin{tabular}{|c|c|c|c|c|c|c|c|}
\hline & \multirow[t]{2}{*}{$\mathrm{PM}_{2.5}$} & \multicolumn{2}{|c|}{$K^{+}$} & \multicolumn{2}{|c|}{$\mathrm{Mg}_{2}^{+}$} & \multicolumn{2}{|c|}{$\mathrm{Ca}_{2}^{+}$} \\
\hline & & Dust_Revised & Dust_Profile & Dust_Revised & Dust_Profile & Dust_Revised & Dust_Profile \\
\hline Mean obs $\left(\mu \mathrm{g} \mathrm{m}^{-3}\right)$ & 81.52 & \multicolumn{2}{|c|}{0.23} & \multicolumn{2}{|c|}{0.19} & \multicolumn{2}{|c|}{2.24} \\
\hline Mean $\operatorname{sim}\left(\mu \mathrm{g} \mathrm{m}^{-3}\right)$ & 44.36 & 0.69 & 0.12 & 0.02 & 0.12 & 3.06 & 1.05 \\
\hline $\operatorname{MB}\left(\mu \mathrm{g} \mathrm{m}^{-3}\right)$ & -37.17 & 0.46 & -0.11 & -0.17 & -0.07 & 0.82 & -1.19 \\
\hline $\operatorname{NMB}(\%)$ & -45.59 & 208.9 & -47.83 & -99.8 & -36.84 & 36.69 & -53.12 \\
\hline$R$ & 0.67 & 0.42 & 0.44 & 0.22 & 0.51 & 0.22 & 0.44 \\
\hline
\end{tabular}

son between observed and simulated $\mathrm{PM}_{2.5}$ concentrations at Duolun and Yulin. The Dust_Revised and Dust_Profile scenarios only differ in terms of their speciation profile for particles. The predicted $\mathrm{PM}_{2.5}$ from the two scenarios are almost identical, so only Dust_Profile is shown in Fig. 5c. The concentration of $\mathrm{PM}_{2.5}$ is underestimated by $-45.59 \%$, which is consistent with the underestimations of $\mathrm{Mg}_{2}^{+}, \mathrm{K}^{+}$, and $\mathrm{Ca}_{2}^{+}$. The evaluation statistics suggest that total $\mathrm{PM}_{2.5}$ is underestimated at Duolun and Yunlin, but $\mathrm{Ca}_{2}^{+}$is overestimated under the default profile. So although the NMB value changes from $36.69 \%$ by the default profile to $-53.12 \%$ for $\mathrm{Ca}_{2}^{+}$by the revised profile, it is highly possible that the revised profile provides a better estimation of the calcium mass contribution since the evaluation statistics for trace metals should be consistent with that for total $\mathrm{PM}_{2.5}$. The overall underestimation of $\mathrm{PM}_{2.5}$ and trace metals is probably due to the underestimation of fine-mode aerosol mass contribution $(20 \%)$ to total dust emission. On the other hand, the simulation bias shown in Fig. 3d suggests a slight overestimation of $\mathrm{PM}_{10}$ at cities close to the Gobi Desert. So it is highly possible that the fine-particle mass contribution configured within CMAQ may be underestimated. Unfortunately, measurements made by Huang et al. (2010) only collected data for total suspended particles (TSPs) and no PM 10 observa- tion is found for Duolun or Yulin. So no reliable conclusion is drawn at this point because the $\mathrm{PM}_{10}$ data are not available at Duolun or Yulin, although the TSPs are measured and indicate that the fine-mode aerosol should have a larger mass contribution (about $40 \%$ in TSP).

\subsection{Impacts of heterogeneous chemistry}

Dust heterogeneous chemistry involves the uptake of gasphase species and the production of secondary inorganic aerosols. In this section we investigate the impacts of implementing dust chemistry in the CMAQ by examining the simulation difference between Dust_Chem and Dust_Profile and the difference between Dust_ChemHigh and Dust_Profile. Figure 6 shows the concentration changes (color contours represent the absolute concentration changes, and dashed lines represent the percentage changes) under heterogeneous chemistry with lower (left column) and upper (right column) limits of uptake coefficients for $\mathrm{O}_{3}$ (first row), $\mathrm{SO}_{2}$ (second row), $\mathrm{SO}_{4}^{2-}$ (third row), $\mathrm{HNO}_{3}$ (fourth row), $\mathrm{NO}_{x}$ (fifth row), and $\mathrm{NO}_{3}^{-}$(sixth row). All variables are averaged for March and April from 2006 to 2010. The spatial distributions shown in Fig. 6 suggest that impacts of dust chemistry are more pronounced in eastern China over the downwind areas than in 
Dust_Chem - Dust_Revised

(a)

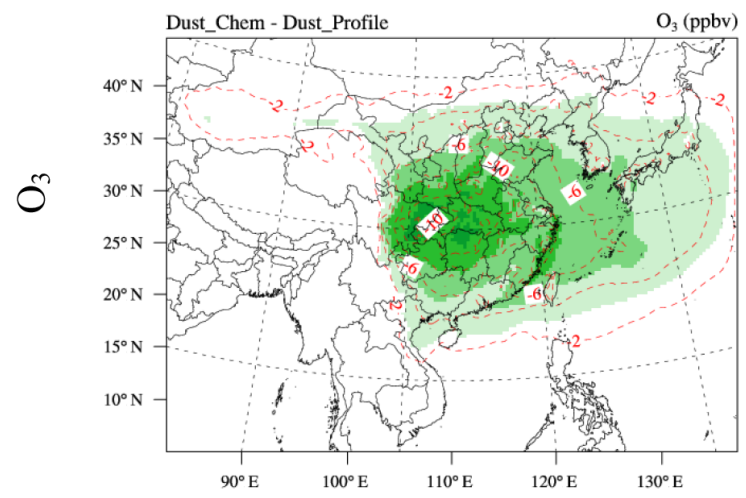

(c)

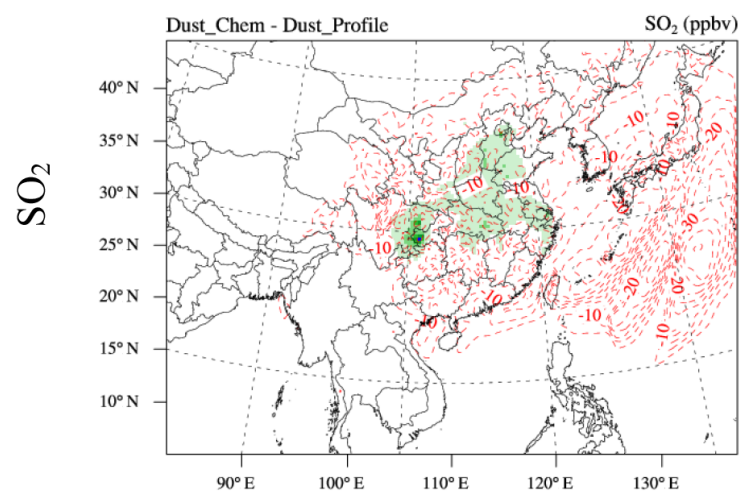

(e)

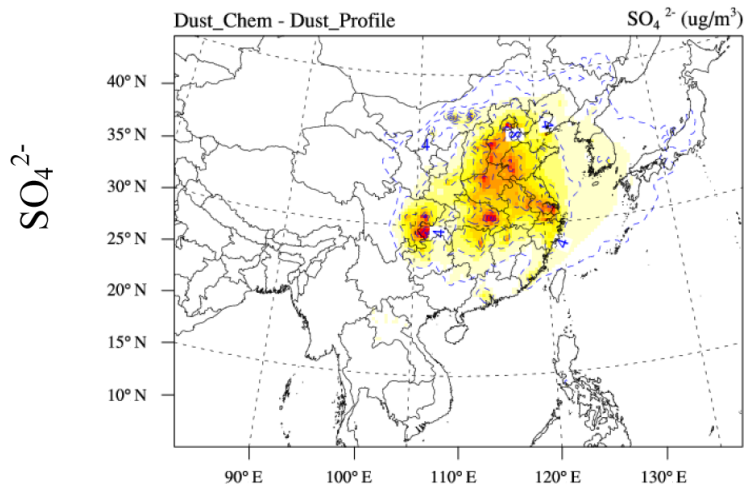

Dust_ChemHigh - Dust_Revised

(b)
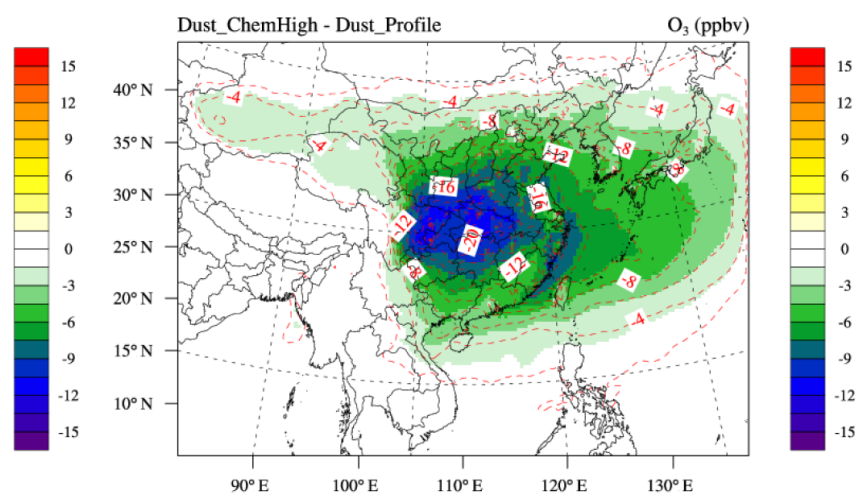

(d)
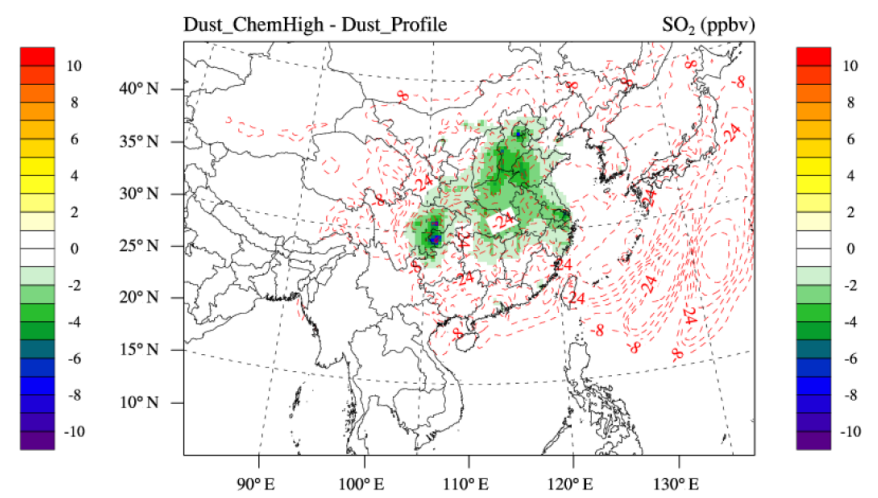

(f)

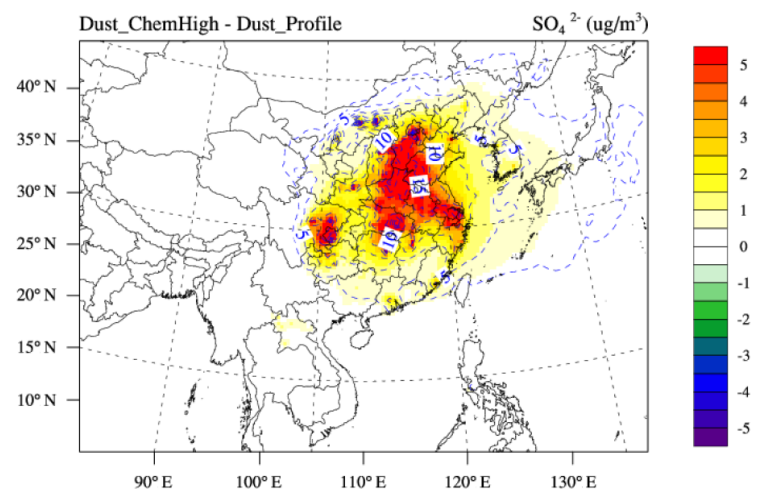

Figure 6. 
(g)

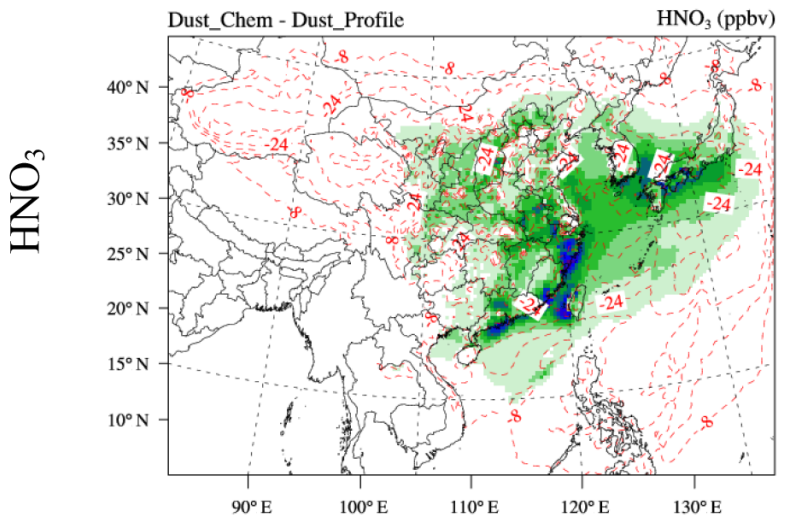

(i)

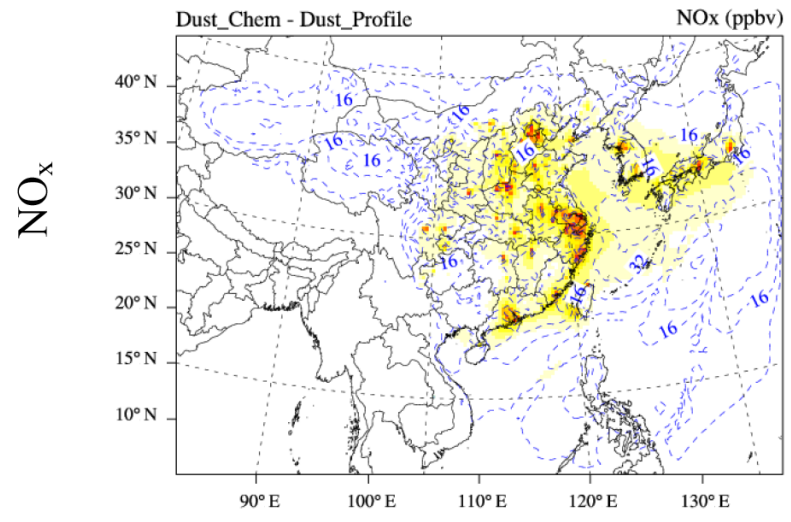

$(\mathrm{k})$

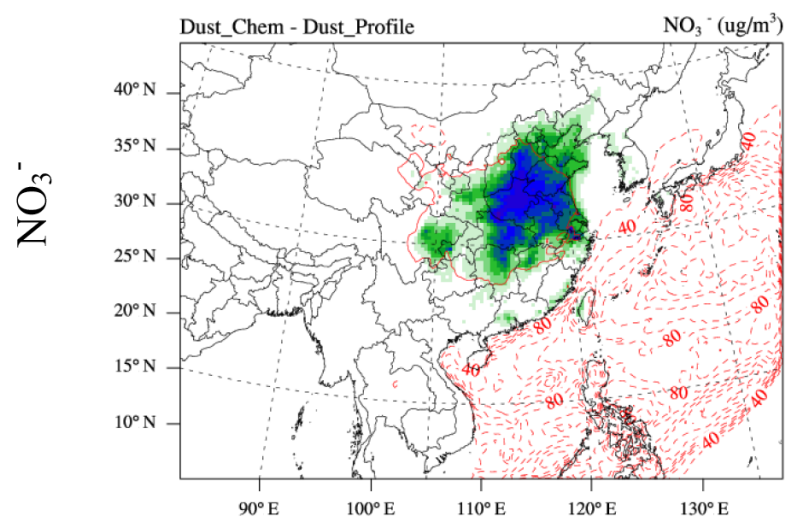

(h)

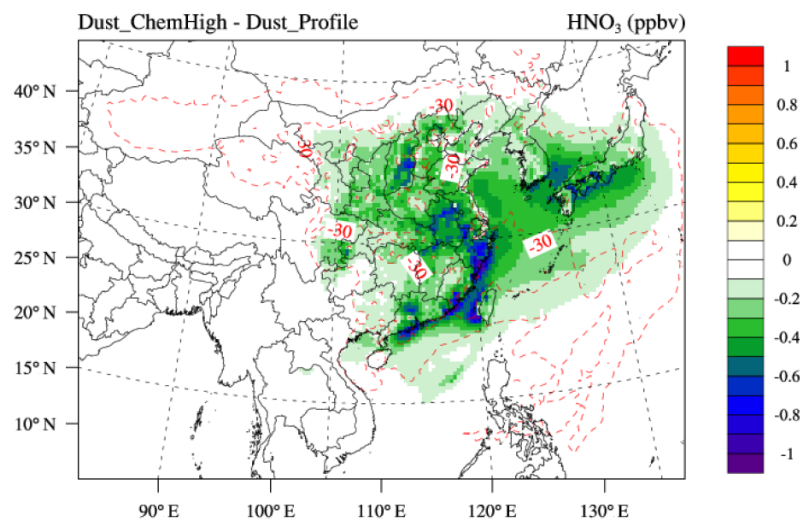

(j)

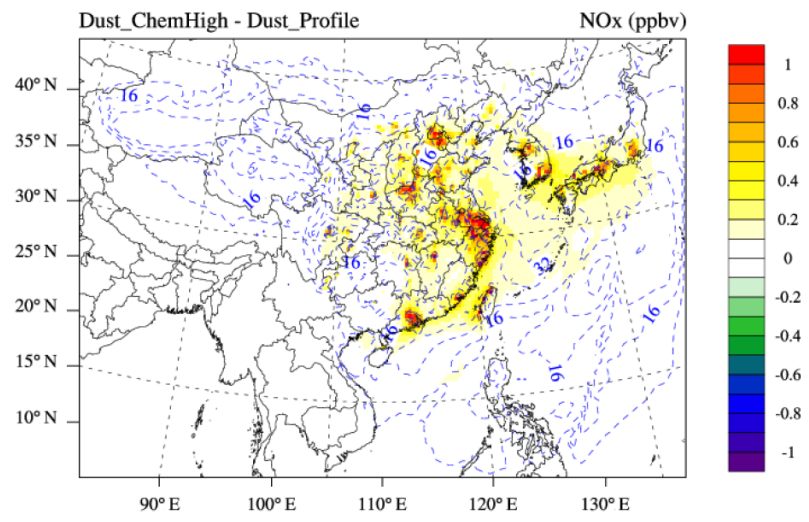

(1)

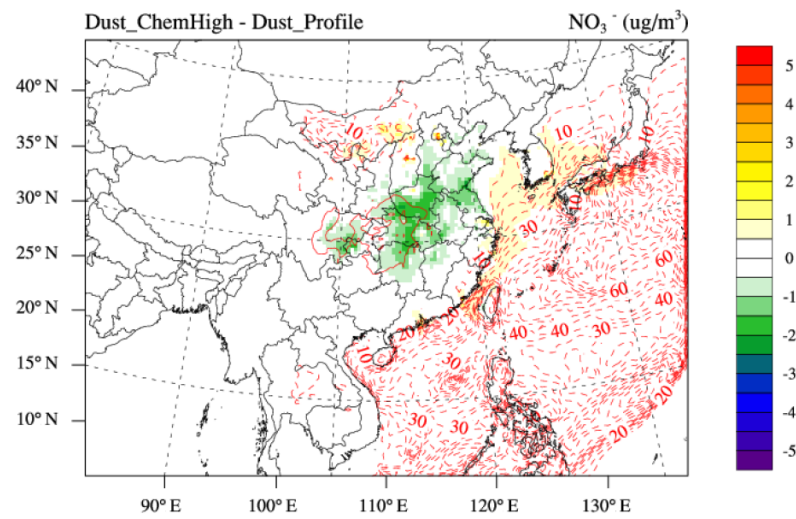

Figure 6. Five-year averages for March and April from 2006 to 2010 of dust heterogeneous chemistry impacts with lower (left column) and upper (right column) uptake coefficients for species $\mathrm{O}_{3}, \mathrm{SO}_{2}, \mathrm{SO}_{4}^{2-}, \mathrm{HNO}_{3}, \mathrm{NO}_{x}$, and $\mathrm{NO}_{3}^{-}$. Color contours represent the absolute concentration changes and dashed contour lines with numbers indicate the percentage changes. 
the dust source area near the deserts. This is because eastern China has intense anthropogenic emissions that help to accelerate the dust chemistry, while the desert areas in northern and western China have much lower concentrations of the reactive gases. Dong and $\mathrm{Fu}(2015 \mathrm{a})$ reported that in spring, $\mathrm{O}_{3}$ concentration is around $30 \mathrm{ppbv}$ and less than $5 \mathrm{ppbv}$ for $\mathrm{NO}_{2}$ and $\mathrm{SO}_{2}$ over the Gobi, while the concentrations over eastern China are 50-60 ppbv for $\mathrm{O}_{3}$ and $10-40 \mathrm{ppbv}$ for $\mathrm{NO}_{2}$ and $\mathrm{SO}_{2}$. A greater proportion of these reactive gases participates in the heterogeneous reactions on the surface of dust particles transported from deserts and thus lead to a more significant impact of dust chemistry over the downwind area instead of over the deserts. Li et al. (2012) also reported that the impact of dust chemistry for $\mathrm{O}_{3}, \mathrm{SO}_{2}$, and $\mathrm{NO}_{2}$ is less than $5 \%$ over the Gobi but up to $30-40 \%$ in eastern China and even higher over the western Pacific. $\mathrm{O}_{3}$ concentration is reduced by $3-6 \mathrm{ppbv}(2-10 \%)$ and $5-11 \mathrm{ppbv}(4-20 \%)$ with the lower and upper limits of uptake coefficients, respectively, due to irreversible Reaction (R1) as listed in Table 3, which agrees well with the values reported by Tang et al. (2004; $20 \%$ and $\mathrm{Li}$ et al. (2012; 5-20\%. Wang et al. (2012) reported lower $\mathrm{O}_{3}$ reduction due to dust chemistry by 3.8 and $7.3 \mathrm{ppbv}$ with lower and upper uptake coefficients, respectively, which could be because of using a different simulation year (2001) with a lower baseline $\mathrm{O}_{3}$ over East Asia. The concentration of $\mathrm{SO}_{2}$ is reduced by $\sim 2 \mathrm{ppbv}(10 \%)$ and $\sim 6 \mathrm{ppbv}(30 \%)$ with lower and upper limits of uptake coefficients, respectively, due to the consumption in reaction $\mathrm{R} 13$, which also leads to the increase in $\mathrm{SO}_{4}^{2-}$ concentration by $\sim 3 \mu \mathrm{g} \mathrm{m}^{-3}(8 \%)$ and more than $5 \mu \mathrm{g} \mathrm{m}^{-3}(15 \%)$ under Dust_Chem and Dust_ChemHigh, respectively. Impacts on $\mathrm{SO}_{2}$ reported by other studies differ moderately by a factor of 2 or more, varying from $55 \%$ by Tang et al. (2004) as the highest, $10-20 \%$ as the medium (Li et al., 2012), and 5-8\% as the lowest (Wang et al., 2012) impact. Different impacts caused by heterogeneous chemistry reported by different studies should mainly be attributed to the different simulation episodes. Tang et al. (2004) focused on dust episodes only in 2001 with lower baseline pollutants from anthropogenic emission; Li et al. (2012) also simulated dust episodes but in 2010; and Wang et al. (2012) simulated the year 2001 but focused on the entirety of April, when the monthly averages of particles are apparently smaller than the values from dust episodes only. Reaction (R7) indicates the consumption and Reaction (R11) indicates the production of $\mathrm{HNO}_{3}$, while the net effect of dust chemistry is found to decrease $\mathrm{HNO}_{3}$ concentration by $0.2-0.8$ ppbv $(8-30 \%)$ as shown in Fig. 6e and f. Our result is comparable with the values reported by Li et al. (2012) as 5-40\% but smaller than that reported by Tang et al. (2004) as 30-70\%. Although the reaction R9 indicates the uptake of $\mathrm{NO}_{x}$ by dust particles, simulation results suggest that $\mathrm{NO}_{x}$ concentration is increased by $0.2-1$ ppbv over eastern China and the west Pacific. The elevation of $\mathrm{NO}_{x}$ concentration should be attributed to the depletion of $\mathrm{O}_{3}$ and the conversion of gas-phase $\mathrm{HNO}_{3}$ back to $\mathrm{NO}_{x}$ (Yarwood et al., 2005). As a result of excessive $\mathrm{SO}_{4}^{2-}$ production from dust chemistry, the concentration of $\mathrm{NO}_{3}^{-}$is decreased under the Dust_Chem scenario due to the thermal-dynamic equilibrium between $\mathrm{SO}_{4}^{2-}-\mathrm{NH}_{4}^{+}-\mathrm{NO}_{3}^{-}$. The equilibrium drives the inorganic aerosols to convert from $\mathrm{NH}_{4} \mathrm{NO}_{3}$ to $\left(\mathrm{NH}_{4}\right)_{2} \mathrm{SO}_{4}$ over eastern China, with intensive anthropogenic $\mathrm{SO}_{2}$ and $\mathrm{NO}_{x}$ emissions from industry and power sector but insufficient $\mathrm{NH}_{3}$ to neutralize all the acid anions. On the other hand, over the western Pacific and Japan, where $\mathrm{SO}_{2}$ and $\mathrm{NO}_{x}$ emissions are less intensive, the concentration of $\mathrm{NO}_{3}^{-}$ is increased slightly due to the production indicated by Reactions (R8) and (R10). Consequently, over eastern and central China, removed $\mathrm{NO}_{3}^{-}$evaporates back to $\mathrm{HNO}_{3}$, which again pushes the gas-phase equilibrium towards the production of $\mathrm{NO}_{x}$ and thus leads to the increase in $\mathrm{NO}_{x}$ but a decrease in $\mathrm{HNO}_{3}$ and $\mathrm{NO}_{3}^{-}$. Meanwhile, with the upper limit of uptake coefficients, the production rate of $\mathrm{HNO}_{3}$ catches up with the removal rate of $\mathrm{NO}_{3}^{-}$, which helps to slow down the decrease in $\mathrm{NO}_{3}^{-}$over China and accelerate the increase in $\mathrm{NO}_{3}^{-}$over the western Pacific and Japan. Our result is consistent with the findings from other studies. Wang et al. (2012) also reported the increase in $\mathrm{NO}_{x}$ and decrease in $\mathrm{HNO}_{3}$ and $\mathrm{NO}_{3}^{-}$ concentrations due to dust chemistry over East Asia. Li et al. (2012) reported that $\mathrm{NO}_{3}^{-}$concentration with a lower uptake coefficient is about $5 \mu \mathrm{g} \mathrm{m}^{-3}(30 \%)$ lower than the base case simulation (with a "best guess" uptake coefficient suggested in Zhu et al., 2010) and $\mathrm{NO}_{3}^{-}$predicted by high uptake coefficient is about $12 \mu \mathrm{g} \mathrm{m}^{-3}(100 \%)$ higher than the base case at Shanghai and Xiamen.

The impact of dust chemistry shown in Fig. 6 suggests comparable results to other modeling assessments, but very few previous studies incorporated observation data to validate further the impact indicated by the model. To evaluate the model's capability to represent dust chemistry and also determine the best-fit uptake coefficients, observations from EANET are used to compared with simulations from Dust_Profile, Dust_Chem, and Dust_ChemHigh. Evaluation statistics are summarized in Table 7. Simulation results from different scenarios for $\mathrm{O}_{3}$ all agree well with observations, as indicated by the statistics. $\mathrm{O}_{3}$ is overpredicted by $1.26 \%$ without dust chemistry in the CMAQ and underpredicted by -1.97 and $-4.43 \%$ with lower and upper uptake coefficients, respectively. $\mathrm{SO}_{2}$ is overpredicted in all scenarios, but the NMB value is reduced from $90.7 \%$ without dust chemistry to 69.8 and $63.7 \%$ with lower and upper uptake coefficients, respectively. Evaluation statistics for $\mathrm{HNO}_{3}$ and $\mathrm{NO}_{x}$ show a similar response to $\mathrm{SO}_{2}$, where heterogeneous chemistry helps to reduce the large overestimations from $109.03 \%$ without dust chemistry to 85.17 and $81.24 \%$ with lower and upper limits of uptake coefficients, respectively. The positive bias for $\mathrm{SO}_{2}$ and $\mathrm{HNO}_{3}$ should be attributed to the overestimated anthropogenic emissions (Dong and Fu, 2015a; Wang et al., 2011). For $\mathrm{NO}_{x}$ evaluation, however, model overes- 
Table 7. CMAQ evaluation against EANET observations for Dust_Profile, Dust_Chem, and Dust_ChemHigh scenarios for species $\mathrm{O}_{3}$, $\mathrm{SO}_{2}$, $\mathrm{SO}_{4}^{2-}, \mathrm{NO}_{x}, \mathrm{HNO}_{3}$, and $\mathrm{NO}_{3}^{-}$.

\begin{tabular}{llrrrrrr}
\hline & & $\begin{array}{r}\mathrm{O}_{3} \\
(\mathrm{ppbv})\end{array}$ & $\begin{array}{r}\mathrm{SO}_{2} \\
(\mathrm{ppbv})\end{array}$ & $\begin{array}{r}\mathrm{SO}_{4}^{2-} \\
\left(\mu \mathrm{g} \mathrm{m}^{-3}\right)\end{array}$ & $\begin{array}{r}\mathrm{NO}_{x} \\
(\mathrm{ppbv})\end{array}$ & $\begin{array}{r}\mathrm{HNO}_{3} \\
(\mathrm{ppbv})\end{array}$ & $\begin{array}{r}\mathrm{NO}_{3}^{-} \\
\left(\mu \mathrm{g} \mathrm{m}^{-3}\right)\end{array}$ \\
\hline Mean obs & 45.81 & 0.59 & 4.38 & 1.75 & 0.43 & 1.52 \\
\hline \multirow{2}{*}{$\mathrm{MB}$} & Dust_Profile & 0.59 & 0.54 & -0.71 & 0.63 & 0.46 & -0.20 \\
& Dust_Chem & -0.92 & 0.42 & 0.60 & 0.67 & 0.36 & -0.03 \\
& Dust_ChemHigh & -2.07 & 0.38 & 1.29 & 0.68 & 0.35 & 0.37 \\
\hline \multirow{2}{*}{ NMB (\%) } & Dust_Profile & 1.26 & 90.70 & -16.28 & 35.61 & 109.03 & -13.07 \\
& Dust_Chem & -1.97 & 69.83 & 13.74 & 37.79 & 85.17 & -1.97 \\
& Dust_ChemHigh & -4.43 & 63.70 & 29.43 & 38.21 & 81.24 & 24.09 \\
\hline \multirow{2}{*}{$R$} & Dust_Profile & 0.63 & 0.68 & 0.79 & 0.69 & 0.65 & 0.71 \\
& Dust_Chem & 0.62 & 0.65 & 0.75 & 0.69 & 0.59 & 0.72 \\
& Dust_ChemHigh & 0.59 & 0.64 & 0.72 & 0.69 & 0.60 & 0.73 \\
\hline
\end{tabular}

timation is increased from $35.61 \%$ under the Dust_Profile scenario to 37.79 and $38.21 \%$ under the Dust_Chem and Dust_ChemHigh scenarios, respectively. The overestimation of $\mathrm{NO}_{x}$ emission should be responsible for the positive bias from the CMAQ as indicated by previous studies (Dong and $\mathrm{Fu}, 2015 \mathrm{a}$ ), but implementing dust chemistry in the model leads to a larger overprediction of $\mathrm{NO}_{x}$. The concentration of $\mathrm{SO}_{4}^{2-}$ is underpredicted by $16.28 \%$ without dust chemistry, yet the simulation overpredicts $\mathrm{SO}_{4}^{2-}$ by 13.74 and $29.43 \%$ under the Dust_Chem and Dust_ChemHigh scenarios, respectively. For $\mathrm{NO}_{3}^{-}$predictions, dust chemistry helps to reduce the underprediction from $13.07 \%$ under the Dust_Profile scenario to $-1.97 \%$ under Dust_Chem scenario. But the simulation is boosted too much with the upper limit of coefficients and it overpredicts $\mathrm{NO}_{3}^{-}$concentration by $24.09 \%$ under the Dust_ChemHigh scenario. Note that EANET data are collected from Japanese sites so that Dust_Chem and Dust_ChemHigh show consistent increases in $\mathrm{NO}_{3}^{-}$, as shown in Fig. 6. Statistics shown in Table 7 suggest that implementing heterogeneous chemistry seems able to improve the CMAQ performance for most of the species except $\mathrm{O}_{3}$ and $\mathrm{NO}_{x}$, but the lower limit of uptake coefficients favors the prediction of $\mathrm{SO}_{4}^{2-}$ and $\mathrm{NO}_{3}^{-}$, and the upper limit of uptake coefficients has a better prediction for $\mathrm{SO}_{4}^{2-}$ and $\mathrm{HNO}_{3}$. Although these statistics show competitive performance between Dust_Chem and Dust_ChemHigh, the lower limit of the uptake coefficient may be more appropriate if we consider the uncertainty within the baseline anthropogenic emissions. With both surface observations and satellite retrievals, Dong and $\mathrm{Fu}$ (2015a) demonstrated that the CMAQ overpredicted $\mathrm{NO}_{x}$ and $\mathrm{SO}_{2}$ over East Asia between 2006 and 2010 by around 30 and $20 \%$, respectively, due to overestimation in anthropogenic emissions. Wang et al. (2011) also report the overestimation of $\mathrm{SO}_{2}$ by $14 \%$ over China. Implementing dust chemistry helps to reduce simulated concentrations of $\mathrm{SO}_{2}, \mathrm{NO}_{x}$, and $\mathrm{HNO}_{3}$, so it can balance part of the positive bias caused by anthropogenic emissions, but the statistics for $\mathrm{SO}_{4}^{2-}$ and $\mathrm{NO}_{3}^{-}$indicate that the counter effect caused by using the upper limit of uptake coefficients may be too excessive and push the balance towards an overestimation of aerosols as a side effect. Consequently, without explicitly excluding the bias within anthropogenic emissions, no reliable conclusion could be achieved regarding the preference of uptake coefficients.

\section{Discussion}

\subsection{Simulating a severe dust storm event}

In this section we probe the capability of the CMAQ to reproduce a severe dust event. Many studies have reported that spring 2010 had the most severe dust storms in recent decades (Bian et al., 2011; Li et al., 2012) due to a nationwide drought in China. $\mathrm{PM}_{10}$ observations were more than $1000 \mu \mathrm{g} \mathrm{m}^{-3}$ at Beijing (Han et al., 2012), $1600 \mu \mathrm{g} \mathrm{m}^{-3}$ at Seoul (Tatarov et al., 2012), and $1200 \mu \mathrm{g} \mathrm{m}^{-3}$ at Taiwan (Tsai et al., 2013). These studies mainly focused on the impact of dust storms on a local scale and the understanding of the emission and transport of the dust event on a regional scale is not well-developed. Here we examined this severe dust event with model simulations, satellite observations, and also surface measurements from multiple networks. Figure 7 displays the MODIS AOD and simulated AOD from the CMAQ Dust_Chem scenario during the severe dust storm episode from 19 to 21 March 2010. Simulated AOD is derived by following the approach described in Huang et al. (2013) for 11:00 LT only to make it consistent with the nadir view time by the MODIS. Spatial distributions of the satellite data agree well with the simulation on a daily scale, indicating that the model can generally reproduce the column density and long-range transport of dust particles. As shown in Fig. 7b, the CMAQ simulation suggests that a large amount of dust 
MODIS

(a) Mar $19^{\text {th }} 2010$

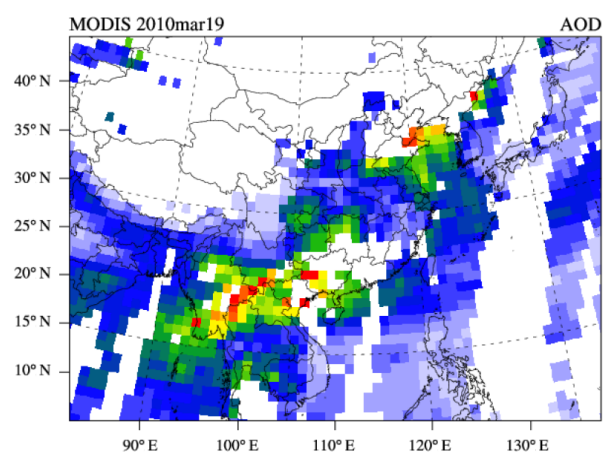

(c) Mar $20^{\text {th }} 2010$

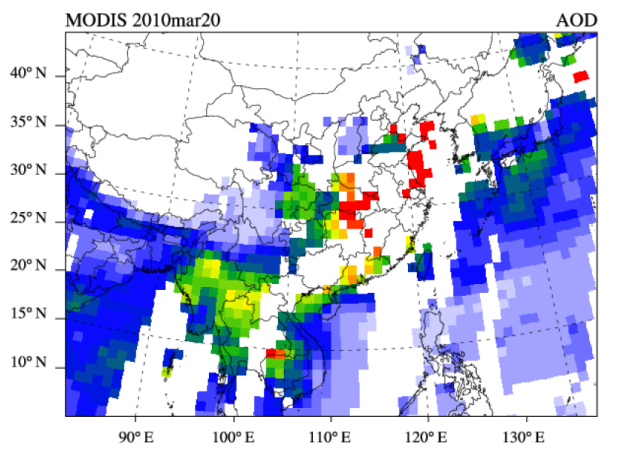

(e) $\operatorname{Mar} 21^{\text {st }} 2010$

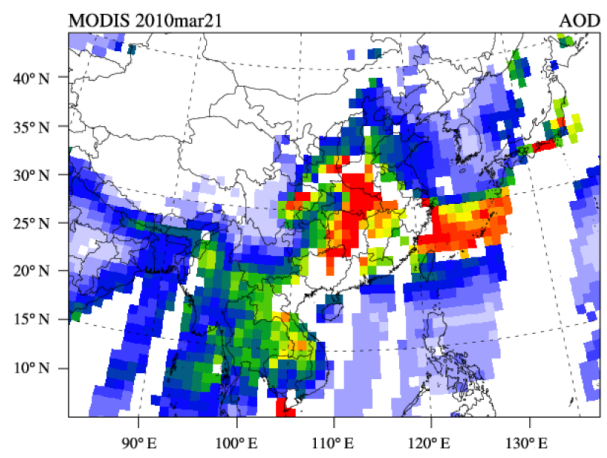

CMAQ

(b) Mar $19^{\text {th }} 2010$
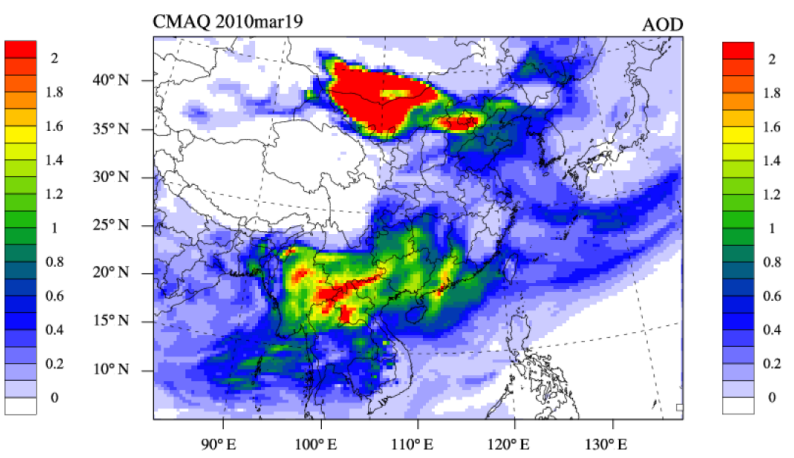

(d) Mar $20^{\text {th }} 2010$

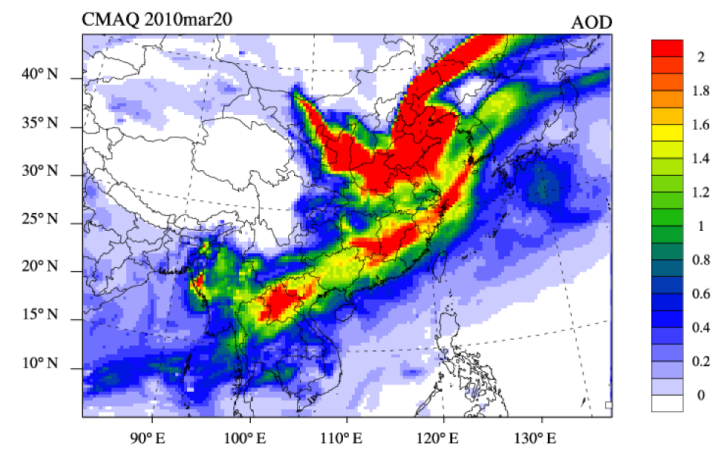

(f) Mar $21^{\text {st }} 2010$

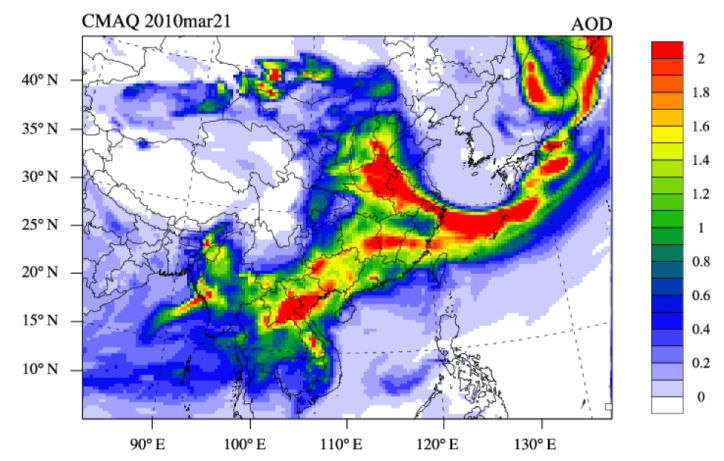

Figure 7. Daily MODIS observed (left column) and CMAQ-simulated AOD (right column) for 19 March (top row), 20 March (middle row), and 21 March (bottom row).

emissions were uplifted on 19 March from the Gobi and increased AOD values over the desert and northern China. The heavy dust emission on 19 March has been identified with an ozone monitoring instrument (OMI) by Li et al. (2011); Fig. 8a also indicates consistently high AOD values around northern China. As the dust plume moved eastwards, both the MODIS and the CMAQ suggest that AOD in the eastern coastal area of China increased from about 0.8 on 19 March to more than 2.0 on 20 March. On 21 March, the majority of the dust plume was pushed eastward and started to build up AOD over the west Pacific and Japan. 

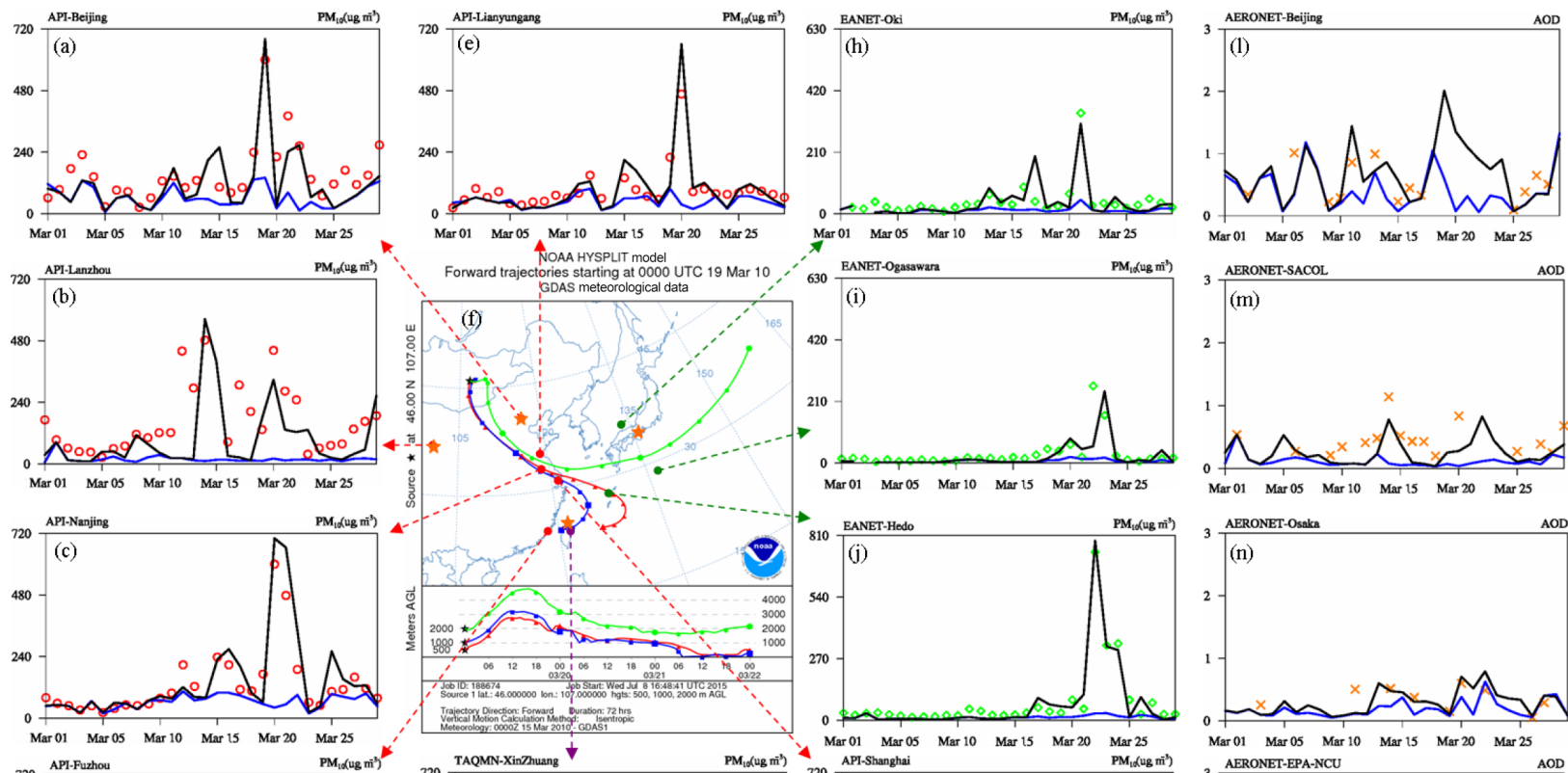

$720 \frac{\text { API-F }}{\text { (d) }}$
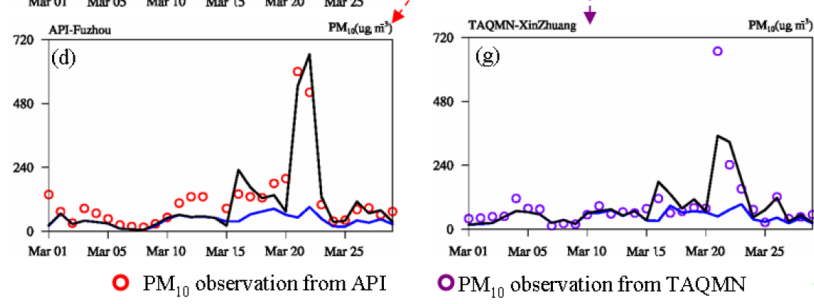

Mar 01 Mar 05 Mar 10 Mar 15 Mar 20 Mar 25

O $\mathrm{PM}_{10}$ observation from TAQMN

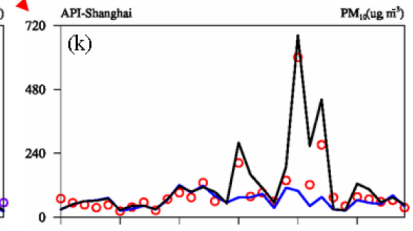

Mar 01 Mar 05 Mar 10 Mar 15 Mar 20 Mar 25

$\triangle \mathrm{PM}_{10}$ observation from EANET

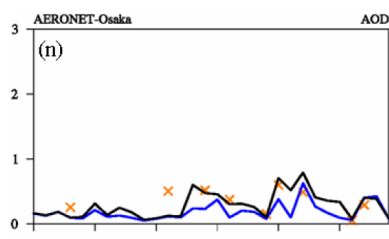

Mar $01 \quad$ Mar 05 Mar $10 \quad$ Mar 15 Mar $20 \quad$ Mar 25

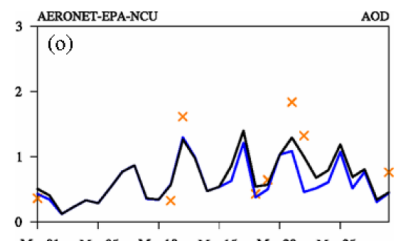

Mar 01 Mar 05 Mar 10 Mar 15 Mar 20 Mar 25

Simulation (Dust_Off)

Simulation (Dust_Chem)

Figure 8. Forward trajectories from (f) HYSPLIT and temporal variations of $\mathrm{PM}_{10}$ and AOD on a daily scale. Comparison between simulated (black lines for Dust_Chem scenario and blue lines for Dust_Off scenario) and observed PM 10 from API (red circles) at (a) Beijing, (b) Lanzhou, (c) Nanjing, (d) Xiamen, (e) Lianyungang, and (k) Shanghai. Comparison between simulations and observed PM 10 from TAQMN (purple circles) at (g) Xinzhuang. Comparison between simulations and observed AOD from EANET (green diamonds) at (l) Beijing, (m) Semi-Arid Climate Observatory Laboratory (SACOL), (n) Osaka, and (o) National Central University (NCU). Locations of cities or stations are indicated by the starting point of the arrows (for $\mathrm{PM}_{10}$ ) or orange stars (for AOD)

To further examine the dust event, a forward trajectory is analyzed to characterize the transport pathway of dust plumes with the Hybrid Single-Particle Lagrangian Integrated Trajectory (HYSPLIT) model from the NOAA/Air Resources Laboratory (Draxler and Rolph, 2015; Rolph, 2015). The movement of air mass was analyzed for $72 \mathrm{~h}$, starting from 00:00 UTC (08:00 LT) on 19 March 2010 in the Gobi, with the forward trajectories shown in Fig. 8f. Air masses at 500 (red line), 1000 (blue line), and $2000 \mathrm{~m}$ (green line) moved southeastward until 20 March, when the higher plume turned east and moved across Japan and the west Pacific, while the lower plumes continued towards the eastern coastal area of China and finally reached Taiwan on 21 March. The HYSPLIT trajectory showed the same consistent transport of dust plumes as the MODIS and the CMAQ AOD analysis.

To understand the impact of dust storms along the transport pathway, we compare the simulated and observed surface level $\mathrm{PM}_{10}$ on a daily scale for all of March 2010 at selected stations along the transport pathway, as indicated

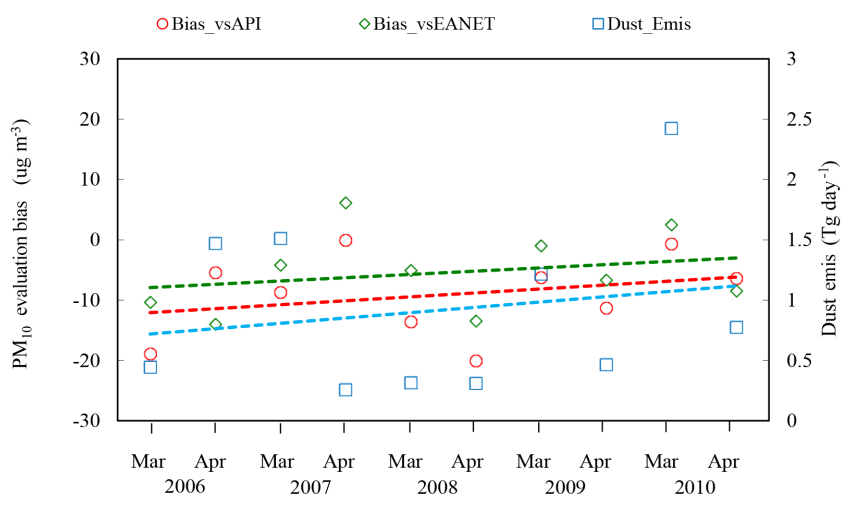

Figure 9. CMAQ predictions of dust emission rate (solid orange rectangles) and simulation bias of $\mathrm{PM}_{10}$ against observations from API (red circles) and EANET (green diamonds). Dashed lines indicate the trends of the variables. 
by Fig. 8f. Simulations from the Dust_Chem (black lines in Fig. 8a-e and g-o) and the Dust_Off scenarios (blue lines in Fig. 8a-e and $\mathrm{g}-\mathrm{O}$ ) are analyzed to examine the model performance. Temporal variations of $\mathrm{PM}_{10}$ with observations from the API (red circles) are examined at Beijing, Lanzhou, Nanjing, Fuzhou, Lianyungang, and Shanghai as shown in Fig. 8a, b, c, d, e, and k, respectively. Observed $\mathrm{PM}_{10}$ concentrations increased rapidly from less than $300 \mu \mathrm{g} \mathrm{m}^{-3}$ on 18 March to more than $600 \mu \mathrm{g} \mathrm{m}^{-3}$ at Beijing and $480 \mu \mathrm{g} \mathrm{m}^{-3}$ at Lianyungang on 19 March. In central and eastern China, concentrations of $\mathrm{PM}_{10}$ peaked on 21 March at Nanjing and Shanghai, and the API reached the measurement ceiling value of $600 \mu \mathrm{g} \mathrm{m}^{-3}$. In southern China, $\mathrm{PM}_{10}$ was also elevated to $600 \mu \mathrm{g} \mathrm{m}^{-3}$ at Xiamen on 22 March. Temporal variation in these cities suggested that $\mathrm{PM}_{10}$ concentrations were elevated with the onset of the dust storm, which moved from the Gobi to southeastern China from 19 to 21 March. $\mathrm{PM}_{10}$ concentrations fell back under $300 \mu \mathrm{g} \mathrm{m}^{-3}$ after the event. Lanzhou reached a peak of $\mathrm{PM}_{10}$ concentration with $500 \mathrm{\mu g} \mathrm{m}^{-3}$ on $14 \mathrm{March}$, which should be attributed to the impact of the dust storm that originated from the Taklamakan. Ling et al. (2011) also reported an observed $507 \mu \mathrm{g} \mathrm{m}^{-3} \mathrm{PM}_{10}$ on 14 March at Lanzhou. Observations from EANET and the TAQMN are also employed to examine the long-range transport of dust over the west Pacific and Taiwan. Temporal variations of $\mathrm{PM}_{10}$ at three EANET sites (green diamonds) including Oki, Ogasawara, and Hedo are shown in Fig. 8h, i, and j, respectively. $\mathrm{PM}_{10}$ concentrations at these sites all showed a consistent increase with the onset of dust on 21 or 22 March. At Xinzhuang, as shown in Fig. 8g, observations from the TAQMN (purple circles) demonstrated that local $\mathrm{PM}_{10}$ was increased from less than $100 \mu \mathrm{g} \mathrm{m}^{-3}$ on 20 March to more than $700 \mu \mathrm{g} \mathrm{m}^{-3}$ on 21 March due to the impact of the dust storm. Simulated $\mathrm{PM}_{10}$ from the Dust_Chem scenario agreed well with observations from different networks all over the domain. Predictions from the Dust_Chem and Dust_Off scenarios were almost the same at all stations during the non-dust period from 1 to 10 March, yet the Dust_Chem scenario was able to reproduce the rapid elevation of $\mathrm{PM}_{10}$ during the dust event. However, a noticeable discrepancy was also found between the Dust_Chem prediction and observations. In general, the CMAQ overpredicted $\mathrm{PM}_{10}$ slightly during the dust event at most of the API sites in China but failed to reproduce the high concentrations at Lanzhou before 15 March and after 20 March. To help understand the model performance in predicting fine particles from dust, daily variations of AOD from the AERONET observations and the CMAQ simulations are also examined at four stations, including Beijing, the SemiArid Climate Observatory Laboratory (SACOL) station at Lanzhou (Ling et al., 2011), Osaka, and EPA-NCU (Taiwan Environment Protection Agency station at National Central University), as shown in Fig. 91, m, n, and o, respectively. Temporal variations of AOD were consistent with the daily changes in $\mathrm{PM}_{10}$ at these cities along the dust plume move- ment trajectory. The highest AOD was found on 14 March at the SACOL station, which was consistent with the rapid increase in $\mathrm{PM}_{10}$ concentrations at Lanzhou. Moderate underestimations of AOD were also found at Lanzhou and EPANCU stations during the dust events, indicating that finemode aerosols were also underestimated over this region. In general, comparisons between the CMAQ and observations from MODIS and surface networks suggest that the model is capable of reproducing the severe dust storm event in terms of the spatial distribution, transport, and concentration of dust particles, with a possible underestimation of dust emission from the Taklamakan.

\subsection{Remaining uncertainties within the modeling system}

Despite the improvements of model performance demonstrated in the previous sections, it is necessary to note that there are some important remaining uncertainties within the modeling system. The first type of uncertainty is related to the anthropogenic emissions. The assessment of the dust prediction capability of the model was primarily performed by comparing the simulation with observations, yet the bias caused by anthropogenic emissions would affect the bias from the dust prediction. So it is difficult to distinguish the uncertainties that arise from dust treatment in the model. Figure 9 displays the dust emission rate $\left(\mathrm{Tg} \mathrm{day}^{-1}\right)$ from the Dust_Chem scenario (blue rectangles, with blue dashed line indicating the trend), the simulation bias of $\mathrm{PM}_{10}$ at the API stations (red circles, with red dashed line indicating the trend), and the simulation bias of $\mathrm{PM}_{10}$ at EANET stations (green diamonds, with green dashed line indicating the trend), with all variables averaged on a monthly scale. The prediction from the CMAQ suggests a slightly increasing trend of dust emission from 2006 to 2010, which is consistent with the decadal increase in dust reported by Kurosaki et al. (2011) due to changes in soil erodibility over Mongolia and northeastern China. The recent decadal trend of dust emission over East Asia remains an open-ended question that will rely on investigations with longer-term simulations. Simulation biases of $\mathrm{PM}_{10}$ agree fairly well with the dust emission at both the API and EANET stations, indicating that the overall underprediction of $\mathrm{PM}_{10}$ over East Asia has a smaller discrepancy for years with stronger dust events. Assuming there is a persistent underestimation of primary PM emissions in the anthropogenic inventory, more dust emissions will apparently help to reduce the modeling bias for total $\mathrm{PM}_{10}$. This is also consistent with previous studies (Wang et al., 2011; Dong and Fu, 2015a) which reported a systematic underestimation of anthropogenic emission of primary particles over China.

The second type of uncertainty lies within the friction velocity threshold $u_{* \mathrm{t}}$, which is affected by the soil moisture fraction, which may be overestimated by the WRF. Although in this study the simulation performance is improved with 
(a) FNL soil moisture fraction

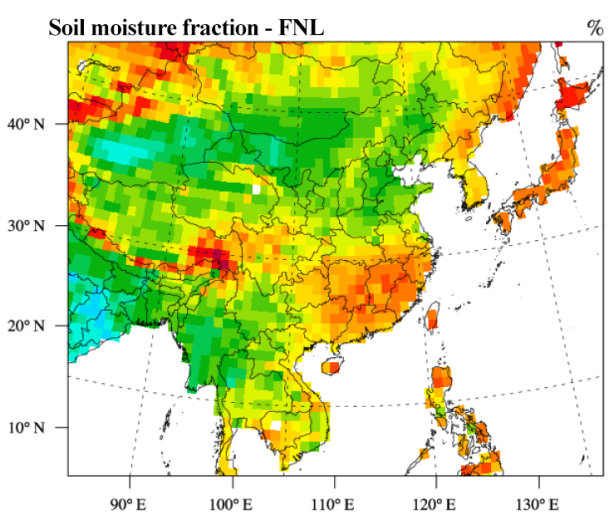

(b) GLDAS soil moisture fraction

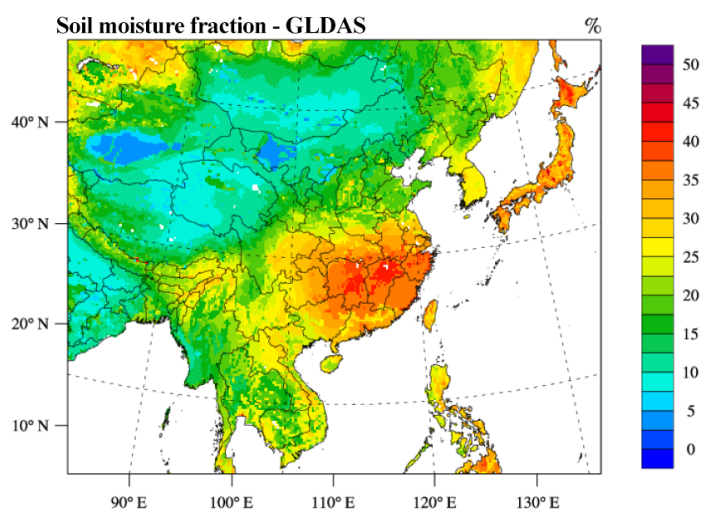

Figure 10. Five-year averages (for March and April) of soil moisture fraction in top $10 \mathrm{~cm}$ soil depth from (a) FNL and (b) GLDAS.

the initial threshold friction velocity constants $u_{* \mathrm{c}}$ adjusted by avoiding the double counting of the soil moisture effect, there are still non-negligible biases as shown in Sect. 3. Both the 5-year average modeling bias shown in Fig. 3d and temporal variations shown in Fig. 8 suggest possible overestimated dust emission from the Gobi and underestimated dust from the Taklamakan. The averaged $u_{* t}$ calculated by the CMAQ is 0.19 and $0.14 \mathrm{~m} \mathrm{~s}^{-1}$ over the Taklamakan and Gobi, respectively, with the soil moisture factor $f_{\text {soilm }}$ being 1.21 and 1.13 , respectively, indicating that the Taklamakan needs higher friction velocity in order to generate dust because of a more significant soil moisture impact. However, some recent field measurement studies suggest that the $u_{* \mathrm{t}}$ in the Taklamakan is lower than that over the Gobi. He et al. (2011) conducted measurements at three sites inside the Taklamakan and reported the value of $u_{* \mathrm{t}}$ as $0.25,0.27$, and $0.21 \mathrm{~m} \mathrm{~s}^{-1}$ at three different sites, and Yang et al. (2011) also reported the value of $u_{* t}$ as $0.24 \mathrm{~m} \mathrm{~s}^{-1}$ at Tazhong $\left(\sim 39.03^{\circ} \mathrm{N}, 83.65^{\circ} \mathrm{E}\right)$. For the Gobi, Li and Zhang (2011) reported the value of $u_{* \mathrm{t}}$ as $0.34-0.42 \mathrm{~m} \mathrm{~s}^{-1}$ based on measurements made in April 2006 and 2008. Field measurements defined $u_{* \mathrm{t}}$ as equal to the value of friction velocity $u_{*}$ when dust concentration is increased by $20 \%$ for at least half an hour ( $\mathrm{Li}$ and Zhang, 2011); thus, the reported values of $u_{* t}$ from the measurement studies are higher than the calculations from the model. But the comparison between the Taklamakan and Gobi measurements suggests that the model may either underestimate $u_{* t}$ in the Gobi or overestimate it in the Taklamakan. Since $f_{\text {soilm }}$ is determined by the soil moisture fraction, we compare the soil moisture from FNL (NCEP final analysis data), which is used to drive WRF in this study, with another reanalysis dataset GLDAS (Global Land Data Assimilation System; Rodell et al., 2004). Figure 10 demonstrates the 5-year averages (for March and April) of the soil moisture fraction in the top $10 \mathrm{~cm}$ from (a) FNL and (b) GLDAS. Soil moisture is estimated to be $10-15 \%$ by FNL in both deserts, while the values from GLDAS are less than 5\% in the Taklamakan and $5-10 \%$ in the Gobi. Zender et al. (2003) reported that soil moisture from NCEP is too high over active dust emission areas and leads to a negative AOD bias of the model on a global scale. With the WRF-NMMB/BSC-Dust model, Haustein et al. (2012) conducted simulations with meteorology driven by FNL and GLDAS over north Africa and reported that the predictions with GLDAS had better agreement with the AERONET's AOD observations due to smaller friction velocity and slightly faster surface wind speed due to lower values of soil moisture. But no such sensitivity studies have been made over East Asia, and unfortunately there are no publicly available observation data for the period of 20062010 to examine the potential overestimation of soil moisture by FNL in our modeling domain. Although we previously reported a consistent negative bias of surface temperature at $2 \mathrm{~m}$ height for 2006-2010, which may be due to excessive soil moisture (Dong and Fu, 2015b), more research efforts are required to verify the uncertainties caused by using FNL soil data.

The last type of uncertainty lies within the mass contribution of fine aerosols within dust emission. Elevated dust particles are distributed into fine- and coarse-mode aerosols with mass ratios of 0.2 and 0.8 , respectively, in the CMAQ dust scheme. In this study, however, the ratio of $\mathrm{PM}_{2.5} / \mathrm{TSP}$ derived from observations at Duolun and Yulin is 0.42 and 0.39 , respectively, indicating that fine particles should have a higher mass contribution within East Asian dust. The data from Huang et al. (2010) indicated that the ratio of $\mathrm{PM}_{2.5}$ / TSP at Tazhong was 0.45 in spring 2007, which suggested an even higher fine-particle mass contribution in the Taklamakan. Model evaluation results shown in Fig. 5 also demonstrate the systematic underestimations of both trace metals and total $\mathrm{PM}_{2.5}$ concentrations in both dust source regions and downwind areas, while the concentrations of $\mathrm{PM}_{10}$ are slightly overestimated near the source region as demonstrated in Fig. 3. Consequently, it is highly possible that the 
ratio of fine particles within dust emission should be higher. But since TSP also includes all large particles $>10 \mu \mathrm{m}$, observations of both $\mathrm{PM}_{2.5}$ and $\mathrm{PM}_{10}$ in active dust regions are urgently needed to help clearly characterize the ratio in the model.

\section{Summary}

The dust module in CMAQ has been further developed in this study. The initial threshold friction velocity constants are revised by removing the double counting of soil moisture in the default parameters; two source-dependent speciation profiles are derived based on local observations of dust emission from the Taklamakan and Gobi deserts; and dust heterogeneous chemistry is implemented. The CMAQ with its revised dust scheme is applied over East Asia for March and April from 2006 to 2010. Based on model evaluations with observation data from both ground-surface networks and satellite retrievals, the revised dust scheme is demonstrated to improve the model performance. Evaluation statistics suggest that $\mathrm{NMB}$ for $\mathrm{PM}_{10}$ simulation is reduced from $-55 \%$ by the default model to $-16 \%$ by the revised model, and NMB for AOD is reduced from -31 to $-22 \%$. Applying source-dependent speciation profiles improves the simulation of trace metals. Heterogeneous chemistry with lower and upper limits of uptake coefficients is also investigated. Although simulations with dust chemistry are demonstrated to agree better with observations than those without chemistry for most of the pollutants, no solid conclusion could be made regarding the preference of uptake coefficients without explicitly excluding the uncertainty caused by anthropogenic emission. This is because simulation with lower coefficients has better agreement with observations for $\mathrm{O}_{3}, \mathrm{SO}_{4}^{2-}$, and $\mathrm{NO}_{3}^{-}$, while simulation with upper coefficients has better performance for $\mathrm{SO}_{2}$ and $\mathrm{NO}_{2}$.

A severe dust storm episode from 19 to 21 March 2010 is investigated to examine the model performance during extreme dust event. The revised CMAQ modeling system successfully reproduces most of the $\mathrm{PM}_{10}$ and AOD observations in both near-source (China) and downwind areas (Japan and Taiwan). But some notable discrepancies are also found, indicating the slight overestimation of dust from the Gobi and underestimation of dust from the Taklamakan. The comparison of the FNL and GLDAS soil moisture fractions indicates that the excessive soil moisture within FNL may be responsible for the higher friction velocity threshold and lower dust emissions calculated by the CMAQ over the Taklamakan. But more sensitive studies with different reanalysis data inputs for WRF and the local soil moisture measurements in the deserts are needed to reach a solid conclusion. In addition, potential uncertainty is also identified within the mass contributions of fine- and coarse-mode particles from dust emission. Evaluation results indicate a consistent underestimation of trace metals and $\mathrm{PM}_{2.5}$ by $30-50 \%$ at Duolun and
Yulin close to the Gobi desert, yet $\mathrm{PM}_{10}$ is generally overestimated slightly in neighboring cities. While measurements from Huang et al. (2010) suggested mass contribution to be $\sim 40 \%$ of fine particles in TSP, the value of $20 \%$ used in the current CMAQ may be too low for dust emissions from the Gobi and Taklamakan. In summary, the model development employed in this study has been demonstrated to enhance the capability of the CMAQ to simulate dust over East Asia regarding the chemical and physical processes involved, which can serve as a useful tool for further investigating the impacts of dust on regional climate over East Asia and elsewhere.

Acknowledgements. We thank NASA GSFC (Grant No. NNX09AG75G) and the National Natural Science Foundation of China (Grant No. 41429501) for their funding support. D. Tong is also particularly grateful for his award of a NASA ROSES grant (NNX13AO45G). We would like to acknowledge Edward J. Hyer for providing biomass burning emission data, and we thank Keiichi Sato and Ayako Aoyagi from the Asia Center for Air Pollution Research for providing the EANET data. We would like to acknowledge George Lin of the National Central University for providing the AOD observations from Taiwan, and we would also like to acknowledge China MEP and Taiwan EPA for providing the observation data and thank NASA for providing the AERONET and MODIS data. We thank the National Institute for Computational Sciences (NICS) for providing the computer sources for the model simulations used in this research.

Edited by: E. Harris

\section{References}

Appel, K. W., Pouliot, G. A., Simon, H., Sarwar, G., Pye, H. O. T., Napelenok, S. L., Akhtar, F., and Roselle, S. J.: Evaluation of dust and trace metal estimates from the Community Multiscale Air Quality (CMAQ) model version 5.0, Geosci. Model Dev., 6, 883-899, doi:10.5194/gmd-6-883-2013, 2013.

Arimoto, R., Kim, Y. J., Kim, Y. P., Quinn, P. K., Bates, T. S., Anderson, T. L., Gong, S., Uno, I., Chin, M., Huebert, B. J., Clarke, A. D., Shinozuka, Y., Weber, R. J., Anderson, J. R., Guazzotti, S. A., Sullivan, R. C., Sodeman, D. A., Prather, K. A., and Sokolik, I. N.: Characterization of Asian Dust during ACE-Asia, Global Planet. Change, 52, 23-56, 2006.

Bauer, S. E., Balkanski, Y., Schulz, M., Hauglustaine, D. A., and Dentener, F.: Global modeling of heterogeneous chemistry on mineral aerosol surfaces: Influence on tropospheric ozone chemistry and comparison to observations, J. Geophys. Res.-Atmos., 109, D02304, doi:10.1029/2003JD003868, 2004.

Bian, H., Tie, X. X., Cao, J. J., Ying, Z. M., Han, S. Q., and Xue, Y.: Analysis of a Severe Dust Storm Event over China: Application of the WRF-Dust Model, Aerosol Air Qual. Res., 11, 419-428, 2011.

Bian, H. S. and Zender, C. S.: Mineral dust and global tropospheric chemistry: Relative roles of photolysis and heterogeneous uptake, J. Geophys. Res.-Atmos., 108, 4672, doi:10.1029/2002JD003143, 2003. 
Blanco, A., Dee Tomasi, F., Filippo, E., Manno, D., Perrone, M. R., Serra, A., Tafuro, A. M., and Tepore, A.: Characterization of African dust over southern Italy, Atmos. Chem. Phys., 3, 21472159, doi:10.5194/acp-3-2147-2003, 2003.

Carmichael, G. R., Tang, Y., Kurata, G., Uno, I., Streets, D., Woo, J. H., Huang, H., Yienger, J., Lefer, B., Shetter, R., Blake, D., Atlas, E., Fried, A., Apel, E., Eisele, F., Cantrell, C., Avery, M., Barrick, J., Sachse, G., Brune, W., Sandholm, S., Kondo, Y., Singh, H., Talbot, R., Bandy, A., Thorton, D., Clarke, A., and Heikes, B.: Regional-scale chemical transport modeling in support of the analysis of observations obtained during the TRACE-P experiment, J. Geophys. Res.-Atmos., 108, 8823, doi:10.1029/2002JD003117, 2003.

Chen, S. Y., Huang, J. P., Zhao, C., Qian, Y., Leung, L. R., and Yang, B.: Modeling the transport and radiative forcing of Taklimakan dust over the Tibetan Plateau: A case study in the summer of 2006, J. Geophys. Res.-Atmos., 118, 797-812, 2013.

Chun, Y. S., Boo, K. O., Kim, J., Park, S. U., and Lee, M.: Synopsis, transport, and physical characteristics of Asian dust in Korea, J. Geophys. Res.-Atmos., 106, 18461-18469, 2001.

Cwiertny, D. M., Young, M. A., and Grassian, V. H.: Chemistry and photochemistry of mineral dust aerosol, Ann. Rev. Phys. Chem., 59, 27-51, 2008.

Darmenova, K. and Sokolik, I. N.: Dust emission and deposition in regional models, Third International Dust Workshop, Leipzig, Germany, September, (September 15, 01-03), 2008.

Davis, J. M., Bhave, P. V., and Foley, K. M.: Parameterization of $\mathrm{N}_{2} \mathrm{O}_{5}$ reaction probabilities on the surface of particles containing ammonium, sulfate, and nitrate, Atmos. Chem. Phys., 8, 52955311, doi:10.5194/acp-8-5295-2008, 2008.

De Longueville, F., Hountondji, Y. C., Henry, S., and Ozer, P.: What do we know about effects of desert dust on air quality and human health in West Africa compared to other regions?, Sci. Total Environ., 409, 1-8, 2010.

Dentener, F. J., Carmichael, G. R., Zhang, Y., Lelieveld, J., and Crutzen, P. J.: Role of mineral aerosol as a reactive surface in the global troposphere, J. Geophys. Res.-Atmos., 101, 22869 22889, 1996.

Dong, X. Y. and Fu, J. S.: Understanding interannual variations of biomass burning from Peninsular Southeast Asia, part I: Model evaluation and analysis of systematic bias, Atmos. Environ., 116, 293-307, 2015a.

Dong, X. Y. and Fu, J. S.: Understanding interannual variations of biomass burning from Peninsular Southeast Asia, part II: Variability and different influences in lower and higher atmosphere levels, Atmos. Environ., 115, 9-18, 2015 b.

Dong, X. Y., Li, J., Fu, J. S., Gao, Y., Huang, K., and Zhuang, G. S.: Inorganic aerosols responses to emission changes in Yangtze River Delta, China, Sci. Total Environ., 481, 522-532, 2014.

Draxler, R. R. and Rolph, G. D.: HYSPLIT (HYbrid Single-Particle Lagrangian Integrated Trajectory) Model access via NOAA ARL READY Website, http://ready.arl.noaa.gov/HYSPLIT.php (last access: 1 August 2015), NOAA Air Resources Laboratory, Silver Spring, MD, 2015.

EANET: EANET Data Report 2006, Acid Deposition Monitoring Network in East Aisa (EANET), 2007.

Engelstaedter, S., Kohfeld, K. E., Tegen, I., and Harrison, S. P.: Controls of dust emissions by vegetation and topographic depres- sions: An evaluation using dust storm frequency data, Geophys. Res. Lett., 30, 1294, doi:10.1029/2002GL016471, 2003.

Fairlie, T. D., Jacob, D. J., Dibb, J. E., Alexander, B., Avery, M. A., van Donkelaar, A., and Zhang, L.: Impact of mineral dust on nitrate, sulfate, and ozone in transpacific Asian pollution plumes, Atmos. Chem. Phys., 10, 3999-4012, doi:10.5194/acp-10-39992010, 2010.

Fécan, F., Marticorena, B., and Bergametti, G.: Parametrization of the increase of the aeolian erosion threshold wind friction velocity due to soil moisture for arid and semi-arid areas, Ann. Geophys., 17, 149-157, doi:10.1007/s00585-999-0149-7, 1999.

Formenti, P., Elbert, W., Maenhaut, W., Haywood, J., and Andreae, M. O.: Chemical composition of mineral dust aerosol during the Saharan Dust Experiment (SHADE) airborne campaign in the Cape Verde region, September 2000, J. Geophys. Res.-Atmos., 108, 8576, doi:10.1029/2002JD002648, 2003.

Forster, P., Ramaswamy, V., Artaxo, P., Berntsen, T., Betts, R., Fahey, D. W., Haywood, J., Lean, J., Lowe, D. C., Myhre, G., Nganga, J., Prinn, R., Raga, G., Schulz, M., and Van Dorland, R.: Radiative Forcing of Climate Change, in Climate Change 2007: The Physical Science Basis. Contribution of Working Group I to the Fourth Assessment Report of the Intergovernmental Panel on Climate Change, edited by: Solomon, S., Qin, D., Manning, M., Chen, Z., Marquis, M., Averyt, K. B., Tignor, M., and Miller, H. L., Cambridge Univ. Press, Cambridge, United Kingdom and New York, NY, USA, 129-234, 2007.

Fu, X., Wang, S. X., Cheng, Z., Xing, J., Zhao, B., Wang, J. D., and Hao, J. M.: Source, transport and impacts of a heavy dust event in the Yangtze River Delta, China, in 2011, Atmos. Chem. Phys., 14, 1239-1254, doi:10.5194/acp-14-1239-2014, 2014.

Gillette, D. A., Adams, J., Endo, A., Smith, D., and Kihl, R.: Threshold Velocities for Input of Soil Particles into the Air by Desert Soils, J. Geophys. Res.-Oc. Atm., 85, 5621-5630, 1980.

Gillette, D. A., Adams, J., Muhs, D., and Kihl, R.: Threshold friction velocities and rupture moduli for crusted desert soils for the input of soil particles into the air, J. Geophys. Res., 87, 90039015, 1982.

Ginoux, P., Chin, M., Tegen, I., Prospero, J. M., Holben, B., Dubovik, O., and Lin, S. J.: Sources and distributions of dust aerosols simulated with the GOCART model, J. Geophys. Res.Atmos., 106, 20255-20273, 2001.

Grell, G. A., Peckham, S. E., Schmitz, R., McKeen, S. A., Frost, G., Skamarock, W. C., and Eder, B.: Fully coupled "online" chemistry within the WRF model, Atmos. Environ., 39, 6957-6975, 2005.

Guenther, A., Karl, T., Harley, P., Wiedinmyer, C., Palmer, P. I., and Geron, C.: Estimates of global terrestrial isoprene emissions using MEGAN (Model of Emissions of Gases and Aerosols from Nature), Atmos. Chem. Phys., 6, 3181-3210, doi:10.5194/acp-63181-2006, 2006.

Han, X., Ge, C., Tao, J. H., Zhang, M. G., and Zhang, R. J.: Air Quality Modeling for a Strong Dust Event in East Asia in March 2010, Aerosol Air Qual. Res., 12, 615-628, 2012.

Haustein, K., Pérez, C., Baldasano, J. M., Jorba, O., Basart, S., Miller, R. L., Janjic, Z., Black, T., Nickovic, S., Todd, M. C., Washington, R., Müller, D., Tesche, M., Weinzierl, B., Esselborn, M., and Schladitz, A.: Atmospheric dust modeling from meso to global scales with the online NMMB/BSC-Dust model - Part 
2: Experimental campaigns in Northern Africa, Atmos. Chem. Phys., 12, 2933-2958, doi:10.5194/acp-12-2933-2012, 2012.

He, Q., Yang, X. H., and Ali, M.: Observation of Dust Emission by Wind Erosion in Taklimakan Desert: Field experiment and preliminary report, J. Desert Res., 31, 315-322, 2011.

Heikes, B. G. and Thompson, A. M.: Effects of Heterogeneous Processes on No3, Hono, and Hno3 Chemistry in the Troposphere, J. Geophys. Res.-Oc. Atm., 88, 883-895, 1983.

Huang, K., Zhuang, G. S., Li, J. A., Wang, Q. Z., Sun, Y. L., Lin, Y. F., and Fu, J. S.: Mixing of Asian dust with pollution aerosol and the transformation of aerosol components during the dust storm over China in spring 2007, J. Geophys. Res.-Atmos., 115, D00K13, doi:10.1029/2009JD013145, 2010.

Huang, K., Fu, J. S., Hsu, N. C., Gao, Y., Dong, X., Tsay, S.-C., and Lam, Y. F.: Impact assessment of biomass burning on air quality in Southeast and East Asia during BASE-ASIA, Atmos. Environ., 78, 291-302, doi:10.1016/j.atmosenv.2012.03.048, 2013.

Huneeus, N., Schulz, M., Balkanski, Y., Griesfeller, J., Prospero, J., Kinne, S., Bauer, S., Boucher, O., Chin, M., Dentener, F., Diehl, T., Easter, R., Fillmore, D., Ghan, S., Ginoux, P., Grini, A., Horowitz, L., Koch, D., Krol, M. C., Landing, W., Liu, X., Mahowald, N., Miller, R., Morcrette, J.-J., Myhre, G., Penner, J., Perlwitz, J., Stier, P., Takemura, T., and Zender, C. S.: Global dust model intercomparison in AeroCom phase I, Atmos. Chem. Phys., 11, 7781-7816, doi:10.5194/acp-11-7781-2011, 2011.

Kandler, K., Benker, N., Bundke, U., Cuevas, E., Ebert, M., Knippertz, P., Rodriguez, S., Schutz, L., and Weinbruch, S.: Chemical composition and complex refractive index of Saharan Mineral Dust at Izana, Tenerife (Spain) derived by electron microscopy, Atmos. Environ., 41, 8058-8074, 2007.

Krueger, B. J., Grassian, V. H., Cowin, J. P., and Laskin, A.: Heterogeneous chemistry of individual mineral dust particles from different dust source regions: The importance of particle mineralogy, Atmos. Environ., 38, 6253-6261, 2004.

Kumar, R., Barth, M. C., Pfister, G. G., Naja, M., and Brasseur, G. P.: WRF-Chem simulations of a typical pre-monsoon dust storm in northern India: influences on aerosol optical properties and radiation budget, Atmos. Chem. Phys., 14, 2431-2446, doi:10.5194/acp-14-2431-2014, 2014.

Kurosaki, Y. and Mikami, M.: Regional difference in the characteristic of dust event in East Asia: Relationship among dust outbreak, surface wind, and land surface condition, J. Meteorol. Soc. Jpn., 83A, 1-18, 2005.

Lam, Y. F. and Fu, J. S.: A novel downscaling technique for the linkage of global and regional air quality modeling, Atmos. Chem. Phys., 9, 9169-9185, doi:10.5194/acp-9-9169-2009, 2009.

Li, J., Wang, Z., Zhuang, G., Luo, G., Sun, Y., and Wang, Q.: Mixing of Asian mineral dust with anthropogenic pollutants over East Asia: a model case study of a super-duststorm in March 2010, Atmos. Chem. Phys., 12, 7591-7607, doi:10.5194/acp-127591-2012, 2012.

Li, J. W., Han, Z. W., and Zhang, R. J.: Model study of atmospheric particulates during dust storm period in March 2010 over East Asia, Atmos. Environ., 45, 3954-3964, doi:10.1016/j.atmosenv.2011.04.068, 2011.

Li, W. Y., Shen, Z. B, Lu, S. H., and Li, Y. H.: Sensitivity Tests of Factors Influencing Wind Erosion, J. Desert Res., 27, 984-993, 2007.
Li, X. and Zhang, H. S.: Research on threshold friction velocities during dust events over the Gobi Desert in northwest China, J. Geophys. Res., 116, D20210, doi:10.1029/2010JD015572, 2011.

Liao, H., Seinfeld, J. H., Adams, P. J., and Mickley, L. J.: Global radiative forcing of coupled tropospheric ozone and aerosols in a unified general circulation model, J. Geophys. Res.-Atmos., 109, D16207, doi:10.1029/2003JD004456, 2004.

Ling, X., Guo, W., Zhao, Q., and Zhang, B.: A case study of a typical dust storm event over the Loess Plateau of northwest China Atmos. Ocean. Sci. Lett., 4, 344-348, 2011.

Liu, M. and Westphal, D. L.: A study of the sensitivity of simulated mineral dust production to model resolution, J. Geophys. Res.Atmos., 106, 18099-18112, 2001.

Ma, C. J., Kasahara, M., Holler, R., and Kamiya, T.: Characteristics of single particles sampled in Japan during the Asian dust-storm period, Atmos. Environ., 35, 2707-2714, 2001.

Marticorena, B., Bergametti, G., Aumont, B., Callot, Y., Doume, C., and Legrand, M.: Modeling the atmospheric dust cycle .2. Simulation of Saharan dust sources. J. Geophys. Res.-Atmos., 102, 4387-4404, 1997.

Martin, R. V., Jacob, D. J., Yantosca, R. M., Chin, M., and Ginoux, P.: Global and regional decreases in tropospheric oxidants from photochemical effects of aerosols, J. Geophys. Res.-Atmos., 108, 4097, doi:10.1029/2002JD002622, 2003.

Matsuki, A., Iwasaka, Y., Shi, G. Y., Zhang, D. Z., Trochkine, D., Yamada, M., Kim, Y. S., Chen, B., Nagatani, T., Miyazawa, T., Nagatani, M., and Nakata, H.: Morphological and chemical modification of mineral dust: Observational insight into the heterogeneous uptake of acidic gases, Geophys. Res. Lett., 32, L22806, doi:10.1029/2005GL024176, 2005.

Miller, R. L., Cakmur, R. V., Perlwitz, J., Geogdzhayev, I. V., Ginoux, P., Koch, D., Kohfeld, K. E., Prigent, C., Ruedy, R., Schmidt, G. A., and Tegen, I.: Mineral dust aerosols in the NASA goddard institute for Space Sciences ModelE atmospheric general circulation model, J. Geophys. Res.-Atmos., 111, D06208, doi:10.1029/2005JD005796, 2006.

Müller, J.-F., Stavrakou, T., Wallens, S., De Smedt, I., Van Roozendael, M., Potosnak, M. J., Rinne, J., Munger, B., Goldstein, A., and Guenther, A. B.: Global isoprene emissions estimated using MEGAN, ECMWF analyses and a detailed canopy environment model, Atmos. Chem. Phys., 8, 1329-1341, doi:10.5194/acp-81329-2008, 2008.

Owen, P. R.: Saltation of uniform grains in air, J. Fluid Mech., 20, 225-242, 1964

Park, S. U. and In, H. J.: Parameterization of dust emission for the simulation of the yellow sand (Asian dust) event observed in March 2002 in Korea, J. Geophys. Res.-Atmos., 108, 4618, doi:10.1029/2003JD003484, 2003.

Pathak, R. K., Wang, T., and Wu, W. S.: Nighttime enhancement of $\mathrm{PM}_{2.5}$ nitrate in ammonia-poor atmospheric conditions in Beijing and Shanghai: Plausible contributions of heterogeneous hydrolysis of $\mathrm{N}_{2} \mathrm{O}_{5}$ and $\mathrm{HNO}_{3}$ partitioning, Atmos. Environ., 45, 1183-1191, 2011.

Phadnis, M. J. and Carmichael, G. R.: Numerical investigation of the influence of mineral dust on the tropospheric chemistry of East Asia, J. Atmos. Chem., 36, 285-323, 2000.

Prospero, J. M.: Long-term measurements of the transport of African mineral dust to the southeastern United States: Impli- 
cations for regional air quality, J. Geophys. Res.-Atmos., 104, 15917-15927, 1999.

Pun, B. K. and Seigneur, C.: Sensitivity of particulate matter nitrate formation to precursor emissions in the California San Joaquin Valley, Environ. Sci. Technol., 35, 2979-2987, 2001.

Qian, W. H., Quan, L. S., and Shi, S. Y.: Variations of the dust storm in China and its climatic control, J. Climate, 15, 12161229, 2002.

Reddy, M. S., Boucher, O., Balkanski, Y., and Schulz, M.: Aerosol optical depths and direct radiative perturbations by species and source type, Geophys. Res. Lett., 32, L12803, doi:10.1029/2004GL021743, 2005.

Reid, E. A., Reid, J. S., Meier, M. M., Dunlap, M. R., Cliff, S. S., Broumas, A., Perry, K., and Maring, H.: Characterization of African dust transported to Puerto Rico by individual particle and size segregated bulk analysis, J. Geophys. Res.-Atmos., 108, 8591, doi:10.1029/2002JD002935, 2003.

Reid, J. S., Hyer, E. J., Prins, E. M., Westphal, D. L., Zhang, J. L., Wang, J., Christopher, S. A., Curtis, C. A., Schmidt, C. C., Eleuterio, D. P., Richardson, K. A., and Hoffman, J. P.: Global Monitoring and Forecasting of Biomass-Burning Smoke: Description of and Lessons From the Fire Locating and Modeling of Burning Emissions (FLAMBE) Program, IEEE J. Sel. Top. Appl., 2, 144-162, 2009.

Rogers, E., Springs, C., Black, G. T., Ferrier, M. B., Gayno, G., Janjic, Z., Lin, Y., Pyle, M., Wong, V., Wu, W. S., and Carley, J.: The NCEP North American Mesoscale modeling system: Recent changes and future plans. Preprints, 23rd Conf. on Weather Analysis and Forecasting/19th Conf. on Numerical Weather Prediction, Omaha, NE, Amer. Meteor. Soc., 2A.4, available at: http:// ams.confex.com/ams/pdfpapers/154114.pdf (last access: 10 June 2015), 2009.

Rodell, M., Houser, P. R., Jambor, U., Gottschalck, J., Mitchell, K., Meng, C. J., Arsenault, K., Cosgrove, B., Radakovich, J., Bosilovich, M., Entin, J. K., Walker, J. P., Lohmann, D., and Toll, D.: The global land data assimilation system, B. Am. Meteorol. Soc., 85, 381-394, doi:10.1175/Bams-85-3-381, 2004.

Rolph, G. D.: Real-time Environmental Applications and Display sYstem (READY) Website, available at: http://ready.arl.noaa.gov (last access: 1 August 2015), NOAA Air Resources Laboratory, Silver Spring, MD, 2015.

Rosenfeld, D., Rudich, Y., and Lahav, R.: Desert dust suppressing precipitation: A possible desertification feedback loop, Proc. Natl. Acad. Sci. USA, 98, 5975-5980, 2001.

Sarwar, G., Roselle, S. J., Mathur, R., Appel, W., Dennis, R. L., and Vogel, B.: A comparison of CMAQ HONO predictions with observations from the northeast oxidant and particle study, Atmos. Environ., 42, 5760-5770, 2008.

Shao, Y. and Dong, C. H.: A review on East Asian dust storm climate, modelling and monitoring, Global Planet. Change, 52, 122, 2006.

Simon, H., Beck, L., Bhave, P. V., Divita, F., Hsu, Y., Luecken, D., Mobley, J. D., Pouliot, G. A., Reff, A., Sarwar, G., and Strum, M.: The development and uses of EPA's SPECIATE database, Atmos. Pollut. Res., 1, 196-206, 2010.

Skamarock, W. C., Klemp, J. B., Dudhia, J., Gill, D. O., Barker, D. M., Duda, M. G., Huang, X. Y., Wang, W., and Powers, J. G.: A Description of the Advanced Research WRF Ver- sion 3. NCAR, NCAR Technical Note NCAR/TN-475+STR, doi:10.5065/D68S4MVH, 2008.

Sun, Y. L., Zhuang, G. S., Wang, Y., Zhao, X. J., Li, J., Wang, Z. F., and An, Z. S.: Chemical composition of dust storms in Beijing and implications for the mixing of mineral aerosol with pollution aerosol on the pathway, J. Geophys. Res.-Atmos., 110, D24209, doi:10.1029/2005JD006054, 2005.

Tang, Y. H., Carmichael, G. R., Kurata, G., Uno, I., Weber, R. J., Song, C. H., Guttikunda, S. K., Woo, J. H., Streets, D. G., Wei, C., Clarke, A. D., Huebert, B., and Anderson, T. L.: Impacts of dust on regional tropospheric chemistry during the ACE-Asia experiment: A model study with observations, J. Geophys. Res.Atmos., 109, D19S21, doi:10.1029/2003JD003806, 2004.

Tatarov, B., Muller, D., Noh, Y. M., Lee, K. H., Shin, D. H., Shin, S. K., Sugimoto, N., Seifert, P., and Kim, Y. J.: Record heavy mineral dust outbreaks over Korea in 2010: Two cases observed with multiwavelength aerosol/depolarization/Raman-quartz lidar, Geophys. Res. Lett., 39, L14801, doi:10.1029/2012GL051972, 2012.

Tsai, F. J., Fang, Y. S., and Huang, S. J.: Case Study of Asian Dust Event on March 19-25, 2010 and Its Impact on the Marginal Sea of China, J. Mar. Sci. Technol., 21, 353-360, 2013.

Tong, D. Q., Bowker, G. E., He, S., Byun, D. W., Mathur, R., and Gillette, D. A.: Development of a windblown dust emission model FENGSHAA description and initial application in the United States, in review, 2016.

Underwood, G. M., Song, C. H., Phadnis, M., Carmichael, G. R., and Grassian, V. H.: Heterogeneous reactions of $\mathrm{NO} 2$ and $\mathrm{HNO} 3$ on oxides and mineral dust: A combined laboratory and modeling study, J. Geophys. Res., 106, 18055-18066, 2001.

Uno, I., Amano, H., Emori, S., Kinoshita, K., Matsui, I., and Sugimoto, N.: Trans-Pacific yellow sand transport observed in April 1998: A numerical simulation, J. Geophys. Res.-Atmos., 106, 18331-18344, 2001.

Usher, C. R., Michel, A. E., and Grassian, V. H.: Reactions on mineral dust, Chem. Rev., 103, 4883-4939, 2003.

Vogel, B., Vogel, H., Kleffmann, J., and Kurtenbach, R.: Measured and simulated vertical profiles of nitrous acid - Part II. Model simulations and indications for a photolytic source, Atmos. Environ., 37, 2957-2966, 2003.

Wang, K., Zhang, Y., Nenes, A., and Fountoukis, C.: Implementation of dust emission and chemistry into the Community Multiscale Air Quality modeling system and initial application to an Asian dust storm episode, Atmos. Chem. Phys., 12, 1020910237, doi:10.5194/acp-12-10209-2012, 2012.

Wang, S. X., Xing, J., Chatani, S., Hao, J. M., Klimont, Z., Cofala, J., and Amann, M.: Verification of anthropogenic emissions of China by satellite and ground observations, Atmos. Environ., 45, 6347-6358, 2011.

Washington, R., Todd, M., Middleton, N. J., and Goudie, A. S.: Dust-storm source areas determined by the total ozone monitoring spectrometer and surface observations, Ann. Assoc. Am. Geogr., 93, 297-313, 2003.

Xing, J., Mathur, R., Pleim, J., Hogrefe, C., Gan, C.-M., Wong, D. C., Wei, C., Gilliam, R., and Pouliot, G.: Observations and modeling of air quality trends over 1990-2010 across the Northern Hemisphere: China, the United States and Europe, Atmos. Chem. Phys., 15, 2723-2747, doi:10.5194/acp-15-2723-2015, 2015. 
Yarwood, J., Rao, S., Yocke, Ma., Whitten, G. Z., and Reyes, S.: Updates to the Carbon Bond Mechanism: CB05, Final Report to the US EPA, RT-0400675, Chapel Hill, NC, December, 2005.

Zender, C. S., Bian, H., and Newman, D.: Mineral Dust Entrainment and Deposition (DEAD) model: Description and 1990s dust climatology, J. Geophys. Res., 108, 4416, doi:10.1029/2002JD002775, 2003.

Zhang, X. Y., Gong, S. L., Zhao, T. L., Arimoto, R., Wang, Y. Q., and Zhou, Z. J.: Sources of Asian dust and role of climate change versus desertification in Asian dust emission, Geophys. Res. Lett., 30, 2272, doi:10.1029/2003GL018206, 2003.

Zhao, B., Wang, S. X., Dong, X. Y., Wang, J. D., Duan, L., Fu, X., Hao, J. M., and Fu, J.: Environmental effects of the recent emission changes in China: Implications for particulate matter pollution and soil acidification, Environ. Res. Lett., 8, 024031, doi:10.1088/1748-9326/8/2/024031, 2013.
Zhao, C., Liu, X., Leung, L. R., Johnson, B., McFarlane, S. A., Gustafson Jr., W. I., Fast, J. D., and Easter, R.: The spatial distribution of mineral dust and its shortwave radiative forcing over North Africa: modeling sensitivities to dust emissions and aerosol size treatments, Atmos. Chem. Phys., 10, 8821-8838, doi:10.5194/acp-10-8821-2010, 2010.

Zhu, H. and Zhang, H. S.: An estimation of the threshold friction velocities over the three different dust storm source areas in northwest China, Acta. Meteorol. Sin., 68, 977-984, 2010 (in Chinese).

Zhuang, G. S., Yi, Z., Duce, R. A., and Brown, P. R.: Link between Iron and Sulfur Cycles Suggested by Detection of Fe(Ii) in Remote Marine Aerosols, Nature, 355, 537-539, 1992. 